\title{
Tuning of Redox Regulatory Mechanisms, Reactive Oxygen Species and Redox Homeostasis under Salinity Stress
}

\section{Sazzad Hossain and Karl-Josef Dietz * \\ Department of Biochemistry and Physiology of Plants, Faculty of Biology, University of Bielefeld, Bielefeld, Germany}

\section{OPEN ACCESS}

Edited by:

Francisco Javier Corpas,

Spanish National Research Council,

Spain

Reviewed by:

Peter Jahns,

Heinrich Heine University Düsseldorf,

Germany

José A. Hernández,

Centro de Edafología y Biología

Aplicada del Segura - Consejo

Superior de Investigaciones

Científicas, Spain

${ }^{*}$ Correspondence:

Karl-Josef Dietz

karl-josef.dietz@uni-bielefeld.de

Specialty section:

This article was submitted to

Plant Physiology,

a section of the journal

Frontiers in Plant Science

Received: 28 February 2016 Accepted: 08 April 2016

Published: 10 May 2016

Citation:

Hossain MS and Dietz K-J (2016)

Tuning of Redox Regulatory

Mechanisms, Reactive Oxygen

Species and Redox Homeostasis

under Salinity Stress.

Front. Plant Sci. 7:548.

doi: 10.3389/fpls.2016.00548
Soil salinity is a crucial environmental constraint which limits biomass production at many sites on a global scale. Saline growth conditions cause osmotic and ionic imbalances, oxidative stress and perturb metabolism, e.g., the photosynthetic electron flow. The plant ability to tolerate salinity is determined by multiple biochemical and physiological mechanisms protecting cell functions, in particular by regulating proper water relations and maintaining ion homeostasis. Redox homeostasis is a fundamental cell property. Its regulation includes control of reactive oxygen species (ROS) generation, sensing deviation from and readjustment of the cellular redox state. All these redox related functions have been recognized as decisive factors in salinity acclimation and adaptation. This review focuses on the core response of plants to overcome the challenges of salinity stress through regulation of ROS generation and detoxification systems and to maintain redox homeostasis. Emphasis is given to the role of $\mathrm{NADH}$ oxidase $(\mathrm{RBOH})$, alternative oxidase (AOX), the plastid terminal oxidase (PTOX) and the malate valve with the malate dehydrogenase isoforms under salt stress. Overwhelming evidence assigns an essential auxiliary function of ROS and redox homeostasis to salinity acclimation of plants.

Keywords: alternative oxidase, antioxidant enzymes, hydrogen peroxide, NADPH oxidase, salinity stress

\section{INTRODUCTION}

Soil salinity is a major environmental stress that strongly impairs crop productivity and harvest quality in the world (Horie and Schroeder, 2004). Significant areas of the cultivated land in more than 100 countries are affected by salinity (Rengasamy, 2006). The quality of approximately $20 \%$ of the world's cultivated area and about $50 \%$ of the world's irrigated lands is affected by salinization (Sairam and Tyagi, 2004). Hence, soil salinity poses a serious threat to crop yield and future food production. Plant responses and tolerance mechanisms to salt stress are a major topic of plant research (Munns and Tester, 2008). In general, high salt concentrations induce ionic imbalances, osmotic stress and oxidative damage ( $\mathrm{Zhu}, 2001)$. Glycophytic plants under salt stress conditions exhibit slow growth, wilting and eventually death (Parida et al., 2004). To survive under stress condition, plants respond and adapt with complex mechanisms that include developmental, morphological, physiological and biochemical strategies (Taji et al., 2004; AcostaMotos et al., 2015) addressing ion homeostasis, osmolyte biosynthesis, compartmentation of toxic ions, and reactive oxygen species (ROS) scavenging systems (Stepien and Klobus, 2005; Flowers and Colmer, 2008). Many genes involved in membrane transport, signal transduction, redox reactions 
and other processes have been identified and characterized (Inan et al., 2004; Zhang et al., 2008). However, the quantitative contribution of the various molecular mechanisms, their qualitative interactions and the integrated functional network underlying plant tolerance to salt stress remain to be determined.

Cell metabolism generates reactive oxygen species (ROS) at low rates as normal side product. Salinity stress often enhances the generation of reactive oxygen species (ROS). This may lead to metabolic disorders, cellular damage, and premature senescence or necrosis (Møller et al., 2007; Jaleel et al., 2009; Miller et al., 2010; Habib et al., 2016). Excessively accumulating ROS may react with suitable targets such as nucleic acids, proteins, lipids and chlorophyll. The main ROS include non-radical molecules like singlet oxygen $\left({ }^{1} \mathrm{O}_{2}\right)$ and hydrogen peroxide $\left(\mathrm{H}_{2} \mathrm{O}_{2}\right)$, as well as free radicals such as superoxide $\left(\mathrm{O}_{2}^{--}\right)$and hydroxyl radicals $\left({ }^{\bullet} \mathrm{OH}\right)$ (Azevedo Neto et al., 2008). Besides their harmful effects ROS act as signaling molecules that regulate plant development, biotic and abiotic stress responses (Mittler et al., 2004). Recent research and considerations have focused on ROS metabolism (Noctor et al., 2014), sensory and signaling networks (Dietz, 2008; Miller et al., 2010; Suzuki et al., 2012; Baxter et al., 2014), as well as the cross-talk with other signaling pathways (Suzuki et al., 2012; Noctor et al., 2014).

The seemingly negative consequences of excess ROS accumulation like lipid peroxidation, oxidation of proteins, damage of nucleic acids, enzyme inhibition, and activation of programmed cell death (PCD) are also linked to signaling since the reaction products transmit information to downstream events (Figure 1; Mishra et al., 2011; Srivastava and Dubey, 2011). The steady state ROS levels depend on the rates of generation and decomposition (Figure 1). Three levels of specificity need to be considered at the level of ROS, their chemical reactivity, as well as their temporal and spatial accumulation pattern. A network of low molecular mass antioxidants and antioxidant enzymes, redox input elements, redox transmitters, redox target proteins and redox sensors orchestrate the readjustment of redox homeostasis and redox-dependent response (Azevedo Neto et al., 2008; Dietz, 2008; Gill and Tuteja, 2010). To understand the redox and ROS balance under salinity we have to consider (i) the ROS generator systems, (ii) the antioxidant defense system, and (iii) the redox regulatory network.

The best studied component is the antioxidant system which includes gene families encoding superoxide dismutases (SOD), catalases (CAT), guaiacol peroxidases (POX), the ascorbateglutathione (ASC-GSH) cycle enzymes [ascorbate peroxidases (APX), monodehydroascorbate reductases (MDHAR), dehydroascorbate reductases (DHAR), glutathione reductases

Abbreviations: AOX, alternative oxidase; APX, ascorbate peroxidase; CAT, catalase; CEF, cyclic electron flow; DHAR, dehydroascorbate reductase; GPX, glutathione peroxidase; GR, glutathione reductase; GSH, glutathione; GST, glutathione-S-transferase; $\mathrm{MDH}$, malate dehydrogenase, NADP- or NADdependent; MDHAR, monodehydroascorbate reductase; PET, photosynthetic electron transport; PRX, peroxiredoxin; POD, guaiacol heme peroxidase; PTOX, plastid terminal oxidase; RBOH, respiratory burst oxidase homologue; RET, respiratory electron transport; ROS, reactive oxygen species; SOD, superoxide dismutase; TRX, thioredoxin.

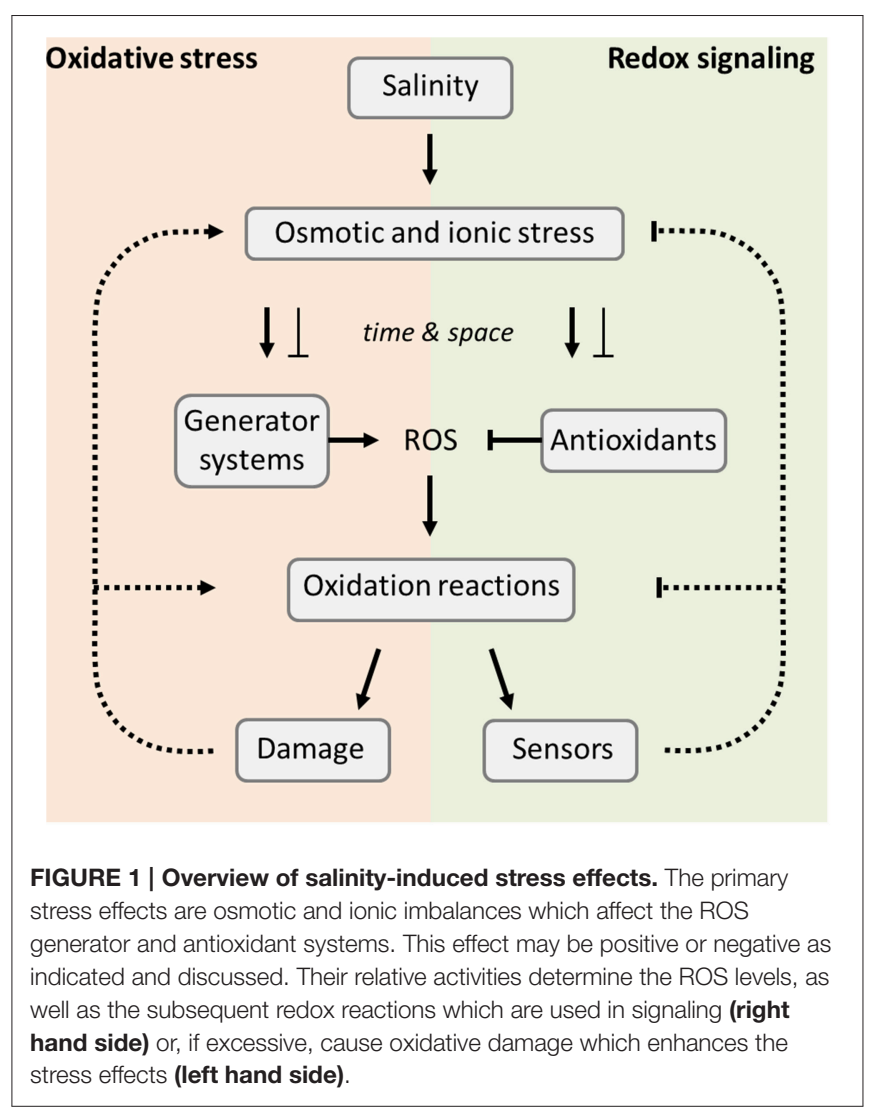

(GR)], glutathione peroxidases (GPX), peroxiredoxins (PRX) and glutathione S-transferases (GST) (Mittler et al., 2004; Azevedo Neto et al., 2008; Munns and Tester, 2008). These antioxidant enzymes are targeted to specific subcellular compartments and reveal stress-specific modulation of their expression as compiled e.g., by Mittler et al. (2004) for $A$. thaliana.

Intensive research on salinity has addressed the ROS generator systems which in a regulated or conditional, but partly less targeted manner control the release of ROS. Metabolic pathways like photorespiration and membraneassociated enzymes determine the rate of ROS generation in plant cells; the NADPH oxidase (respiratory burst oxidase homolog: RBOH) (Keller et al., 1998), mitochondrial alternative oxidase (AOX) (Considine et al., 2002) and plastid terminal oxidase (PTOX) (Stepien and Johnson, 2009). Additional layers of defense and regulation modulate the redox state of the cell and control the subcellular redox balance. Malic acid and oxaloacetic acid represent a redox pair of metabolites linked by malate dehydrogenases $(\mathrm{MDH})$, e.g., the NADP-MDH in the chloroplast. Exchange of malic acid and oxaloacetic acid by membrane transport among compartments allows for indirect transfer of reducing equivalents. This process is known as malate valve (Scheibe et al., 2005). The tightly regulated plastid NADP-MDH controls the export of excess reducing power from the photosynthesizing chloroplast and thereby relieves overreduction of the photosynthetic electron transport chain and thus generation of ROS. 
The significance of these enzymes and mechanisms in salt tolerance is still a matter of controversy. Often, regulatory patterns are difficult to interpret; e.g., upregulation of antioxidant enzymes may represent the response to manifested oxidative stress. On the other hand, upregulation of antioxidant enzymes may be considered as proactive acclimation response which results in lower ROS levels and higher tolerance to oxidative stress. Consequentially high antioxidant enzyme activities have been associated with salt tolerance as well as salt sensitivity. With that said, this review aims to provide a critical update on redox regulation, oxidative stress and their implications in salt stress acclimation and damage development.

\section{GENERATION OF ROS UNDER SALINITY STRESS IN PLANT}

Salt stress interferes with carbon metabolism and thereby fosters ROS generation. Stomatal conductance decreases during salt stress and lowers transpiration. The stomatal movement is linked to ion redistribution, alkalization and ABA accumulation (Geilfus et al., 2015). Restricted gas exchange limits $\mathrm{CO}_{2}$ uptake, lowers intercellular $\mathrm{CO}_{2}$ concentration and $\mathrm{CO}_{2}$ availability for the Calvin cycle. As a consequences the pool of oxidized $\mathrm{NADP}^{+}$ (as final electron acceptor at PSI) is depleted and electrons are transferred to $\mathrm{O}_{2}$ to generate $\mathrm{O}_{2}^{\bullet-}$ (Mehler, 1951). Following nonenzymatic or enzymatic dismutation by superoxide dismutase (SOD), $\mathrm{H}_{2} \mathrm{O}_{2}$ can be converted to the extremely reactive hydroxyl radicals $\left({ }^{\bullet} \mathrm{OH}\right)$ in the Fenton-/Haber-Weiss-reaction. Insufficient energy dissipation in photosynthesis causes formation of ${ }^{1} \mathrm{O}_{2}$ from triplet chlorophyll $(\mathrm{Chl})$ especially in the reaction center of photosystem II (Krieger-Liszkay, 2005). The decrease in the $\mathrm{CO}_{2} / \mathrm{O}_{2}$-ratio in the mesophyll enhances photorespiration in C3-plants and stimulates $\mathrm{H}_{2} \mathrm{O}_{2}$ generation in the peroxisome (Wingler et al., 2000; Ghannoum, 2009). Photorespiration accounts for over $70 \%$ of the $\mathrm{H}_{2} \mathrm{O}_{2}$ production under osmotic stress (Noctor et al., 2002). Early studies on respiratory electron transport (RET) reported increased rates of electron transfer to $\mathrm{O}_{2}$ and thus of respiratory $\mathrm{O}_{2}$ consumption under salt stress (Fry et al., 1986; Moser et al., 1991). $\mathrm{O}_{2}^{--}$is generated when RET is overreduced. The generated $\mathrm{O}_{2}^{\bullet-}$ is dismutated to $\mathrm{H}_{2} \mathrm{O}_{2}$ which is subsequently reduced to water by catalases, class I peroxidases (APXs), class III peroxidases (POXs) and thiol peroxidases. Salinity stress activates the cell membrane-bound RBOH (Rejeb et al., 2015a; Tsai et al., 2005) and the apoplastic diamine oxidase (Waie and Rajam, 2003). Both mechanisms contribute to the generation of ROS in the apoplastic space. In other cases $\mathrm{RBOH}$ activity was inhibited under salt stress (Rodríguez et al., 2009). In salt-stressed maize leaves (150 $\mathrm{mM} \mathrm{NaCl}$ in hydroponics), levels of apoplastic spermidine and spermine increased several times and the apoplastic polyamine oxidase allowed for converting the polyamines to 1,3-diaminopropane and $\mathrm{H}_{2} \mathrm{O}_{2}$ (Rodríguez et al., 2009). This mechanism enables cell wall loosening by generation of ${ }^{\bullet} \mathrm{OH}$ and sustains leaf blade growth even if $\mathrm{RBOH}$ is inhibited (Rodríguez et al., 2009). Other ROS-generating enzymes include oxalate oxidase and amine oxidase. In context of salinity much work has focused on $\mathrm{RBOH}$-like enzymes, the major enzymatic route of ROS synthesis in plant cells (Sharma et al., 2012), which will be discussed below in more detail.

Under salinity stress each type of organelle employs different mechanisms of ROS production. The subcellular and cellular sites of ROS production decisively determine their signaling action. Thus, ROS are produced in particular in the PET of chloroplasts, the RET in mitochondria, various oxidases in peroxisome and the NADPH oxidase $(\mathrm{RBOH})$ in the plasma membrane (Figure 2). In addition reactions in the endomembrane system and the apoplast/cell wall also contribute to ROS generation (Table 1). Localized production in specific micro-compartments and the buffering action of multiple antioxidant mechanisms fine-tune the concentrations of ROS at particular sites of the cell under salt stress. Such mechanisms could delimit the response to localized "hot-spots."

\section{SCAVENGING OF ROS UNDER SALINITY STRESS IN PLANT}

Superoxide dismutase (SOD) belongs to the group of metalloenzymes and functions as an important enzyme in the first line of antioxidant defense. MnSOD, $\mathrm{Cu} / \mathrm{ZnSOD}$ and FeSOD dismutate $\mathrm{O}_{2}^{\bullet-}$ into $\mathrm{H}_{2} \mathrm{O}_{2}$ and $\mathrm{O}_{2}$ (Rios-Gonzalez et al., 2002; Tuna et al., 2008). Elevated SOD activity often appears to enhance plant tolerance to oxidative stress (Gupta et al., 1993). ${ }^{1} \mathrm{O}_{2}$ can be quenched by $\beta$-carotene or $\alpha$-tocopherol, but also can react with the D1 protein of photosystem II as a sensitive protein target (Krieger-Liszkay, 2005). Among the antioxidant enzymes, catalase (CAT) was discovered first and dismutates two molecules of $\mathrm{H}_{2} \mathrm{O}_{2}$ into water and oxygen. Peroxidases are classified as heme or thiol (or selenol) peroxidases and reduce $\mathrm{H}_{2} \mathrm{O}_{2}$ at the expense of an alternative electron donor (Dietz, 2016). Thiol peroxidases use thiol electron donors such as thioredoxin (TRX), glutaredoxin (GRX), glutathione or in rare cases ascorbate to convert $\mathrm{H}_{2} \mathrm{O}_{2}$ to $\mathrm{H}_{2} \mathrm{O}$. Ascorbate peroxidase (APX) catalyzes the primary step in the classical water-water cycle (Asada, 1992) where DHAR and GR, a flavoenzyme which contains an essential disulfide group, catalyze the regeneration of ascorbate from dehydroascorbate using glutathione and finally NADPH as reductants. The regeneration of ascorbate from monodehydroascorbate is also carried out by MDHAR using NADH as reducing power. GPX, some GST and PRX reduce $\mathrm{H}_{2} \mathrm{O}_{2}$ and organic hydroperoxides through ascorbateindependent thiol-mediated pathways using nucleophiles such as GSH, thioredoxin (TRX) or glutaredoxins (GRX) (Asada, 1992; Dietz et al., 2006; Noctor et al., 2014). Transcript levels of TRX, Mn-SOD, AOX, and PRXIIF increased under short-term salinity conditions (Marti et al., 2011). The mitochondrial PsTRXo1 increases in pea leaves in response to long-term salinity (Marti et al., 2011). PsTRXo1 and PRXIIF provide the cell with a mechanism to protect mitochondria from oxidative stress together with Mn-SOD and AOX. Mitochondrial TRX-o1, PRXIIF and sulfiredoxins participate in the establishment of salt tolerance through a fine-regulated mechanism involving the post-translational modifications of $S$-glutathionylation and S-nitrosylation (Lázaro et al., 2013). 


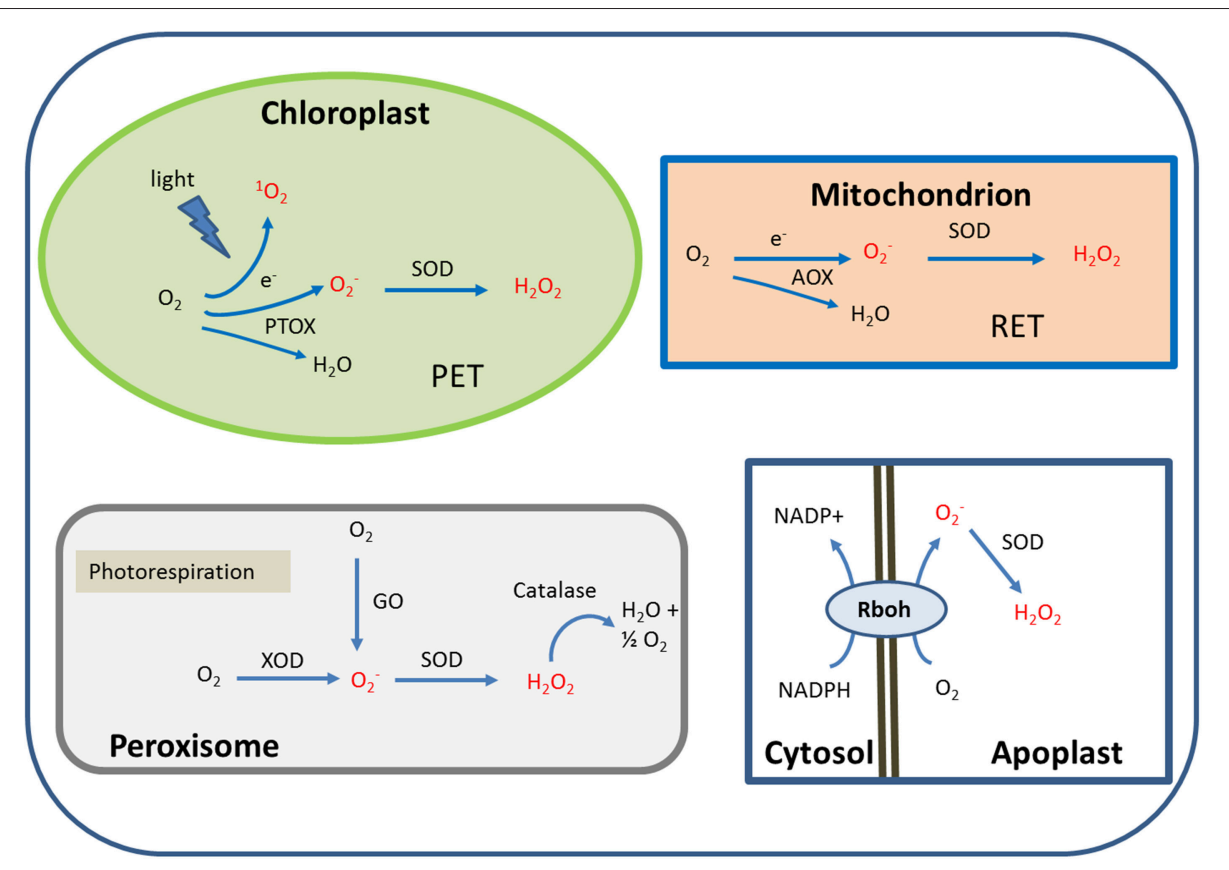

FIGURE 2 | Simplified scheme illustrating the predominant ROS generation sites in plant cell under salinity stress. These sites are photosynthesis in chloroplasts, respiration in mitochondria, photorespiration in peroxisomes and NADH oxidation at the plasma membrane. AOX, alternative oxidase; GO, glycolate oxidase; PET, photosynthetic electron transport; PTOX, plastid terminal oxidase; RBOH, respiratory burst oxidase homolog; RET, respiratory electron transport; SOD, superoxide dismutase; XOD, xanthine oxidase.

TABLE 1 | Generation sites and origin of reactive oxygen species (ROS) in plants.

\begin{tabular}{|c|c|c|}
\hline Location & Key sources of ROS in cell & References \\
\hline Chloroplast & $\begin{array}{l}\text { PET (PSI, PQ, and PSII) } \\
\text { Chlorophyll pigments }\end{array}$ & Elstner, 1991; Cleland and Grace, 1999 \\
\hline Mitochondrion & $\begin{array}{l}\text { Complexes of RET } \\
\text { Enzymes, e.g., aconitase, 1-galactono- } \gamma \text { lactone dehydrogenase (GAL) }\end{array}$ & Andreyev et al., 2005; Rasmusson et al., 2008 \\
\hline Peroxisome & $\begin{array}{l}\text { Glycolate oxidase (GO), fatty acid } \beta \text {-oxidation, flavine oxidases, } \\
\text { xanthine oxidase (XOD), peroxisomal NADPH: cytochrome P450 } \\
\text { reductase and ETC composed of a flavoprotein, NADH and Cyt b }\end{array}$ & López-Huertas et al., 1999; Baker and Graham, 2002 \\
\hline Plasma membrane & NADPH oxidase and menadione (quinone reductase) & Heyno et al., 2011 \\
\hline Apoplast & $\begin{array}{l}\text { Cell wall-associated oxalate oxidase (germine) and amine oxidase-like } \\
\text { enzymes }\end{array}$ & Wojtaszek, 1997; Cona et al., 2006 \\
\hline Cell wall & $\begin{array}{l}\text { Cell-wall-associated peroxidase in the presence of NADH and diamine } \\
\text { oxidases }\end{array}$ & Gross, 1977; Martinez et al., 1998 \\
\hline Endoplasmatic reticulum & NAD(P)H-dependent electron transport involving Cyt P450 & Mittler, 2002 \\
\hline
\end{tabular}

The link between salt tolerance and increased activities of antioxidant enzymes has frequently been established (Zeng et al., 2003; Liu et al., 2011; Table 2). Stepien and Klobus (2005) compared oxidative stress in salt-stressed wheat and maize by assessing lipid peroxidation and activities of antioxidant enzymes. Maize suffered less oxidative stress than wheat. The constitutive and salt stress-inducible activities of SOD, APX and GR were higher in maize than in wheat. The authors suggested that the higher tolerance of maize is based on two mechanisms, namely lower ROS production in C4photosynthesis and higher activities of the antioxidant enzymes.
Photorespiration is strongly induced by salt stress in C3 but not in C4 and CAM plant (Cushman and Bohnert, 1997). Flaveria, Alternanthera, Parthenium, Panicum and Moricandia species are some species with $\mathrm{C} 3-\mathrm{C} 4$ intermediate photosynthesis which are able to efficiently recycle photorespired $\mathrm{CO}_{2}$ which lowers the rate of photorespiration (Monson et al., 1984; Devi and Raghavendra, 1993). C3 species examined had high intrinsic levels of photorespiration whereas the $\mathrm{C} 3-\mathrm{C} 4$ intermediate species (primarily by refixing photorespired $\mathrm{CO}_{2}$ ), C4-like and C4 species (via selective localization of ribulose-1,5-bisphosphate carboxylase in bundle sheath cells and operation of a $\mathrm{CO}_{2}$ 
TABLE 2 | Antioxidant enzymes reported to be regulated in plants under salinity stress.

\begin{tabular}{|c|c|c|}
\hline Antioxidant enzymes* & Plant species & References \\
\hline SOD, CAT, GPX, APX, GR, MDHAR, DHAR & Oryza sativa & Mishra et al., 2013 \\
\hline CAT, SOD, GR & Olea europaea & Valderrama et al., 2006 \\
\hline APX, MDHAR, DHAR, GR & Oryza sativa & Hossain et al., 2013 \\
\hline \multirow[t]{3}{*}{ SOD } & Triticum aestivum & Borzouei et al., 2012 \\
\hline & Oryza sativa & Tanaka et al., 1999 \\
\hline & Cakile maritime & Ellouzi et al., 2011 \\
\hline GR, SOD, POX, CAT & Helianthus annuus, Zea mays & Rios-Gonzalez et al., 2002 \\
\hline SOD, APX, DHAR & Nicotiana tabacum & Lee et al., 2007 \\
\hline APX, GR & Oryza sativa & Tsai et al., 2005 \\
\hline \multirow[t]{5}{*}{ APX } & Nicotiana tabacum & Badawi et al., 2004; Li et al., 2009; Sun et al., 2010 \\
\hline & Pisum sativum, Lycopersicon esculentum & Wang et al., 2005 \\
\hline & Hordeum vulgare & Shi et al., 2001 \\
\hline & Arabidopsis thaliana & Lu et al., 2007 \\
\hline & Ipomoea batatas & Lin and Pu, 2010 \\
\hline DHAR, GR, MDHAR, APX, SOD & Pisum sativum & Hernández et al., 2001 \\
\hline CAT, POX, APX, GR, SOD & Echinochloa crusgalli & Abogadallah et al., 2009 \\
\hline MDHAR & Nicotiana tabacum & Eltayeb et al., 2007 \\
\hline DHAR & Lotus japonicas & Rubio et al., 2009 \\
\hline GR & Nicotiana tabacum) & Aono et al., 1993 \\
\hline RBOHD/F & Arabidopsis thaliana & Ma et al., 2012 \\
\hline RBOHF & Arabidopsis thaliana & Jiang et al., 2012 \\
\hline \multirow[t]{4}{*}{ AOX } & Citrus sinensis (cvs. Carvalhal tangor) & Ferreira et al., 2008 \\
\hline & Glycine max & Hilal et al., 1998 \\
\hline & Arabidopsis thaliana & Smith et al., 2009; Wang et al., 2010 \\
\hline & Hordeum vulgare & Jolivet et al., 1990 \\
\hline OsAOX1a & Oryza sativa & Li et al., 2013 \\
\hline OsAOX1b & Oryza sativa & Li et al., 2013 \\
\hline OsAOX1c & Oryza sativa & Li et al., 2013 \\
\hline \multirow[t]{3}{*}{ NADH-MDH } & Oryza sativa & Kumar et al., 2000 \\
\hline & Mesembryanthemum crystallinum & Cushman, 1993; Gawronska et al., 2013 \\
\hline & Arabidopsis thaliana & Hebbelmann et al., 2012 \\
\hline PTOX & Thellungiella halophila & Stepien and Johnson, 2009 \\
\hline \multirow[t]{4}{*}{ PTOX } & Arabidopsis thaliana & Josse et al., 2003; Stepien and Johnson, 2009 \\
\hline & Oryza sativa & Kong et al., 2003 \\
\hline & Haematococcus pluvialis & Wang et al., 2009 \\
\hline & Thellungiella salsuginea & Wiciarza et al., 2015 \\
\hline
\end{tabular}

*Bold: upregulated under salt stress, underlined: down-regulated, normal: unchanged. 
pump via the $\mathrm{C} 4$ pathway) maintained low apparent rates of photorespiration (Dai et al., 1996). In another study, RiosGonzalez et al. (2002) reported higher activities of GR, SOD, POD and CAT in sunflower leaves than in maize under salt stress. C4-like Flaveria brownie and C4 Flaveria bidentis are able to prevent oxidative damage by stress by increased enzymatic and non-enzymatic antioxidants, as compared to C3 (Flaveria robusta) and C3-C4 intermediate (Flaveria anomala) (Uzilday et al., 2014). Higher water use efficiency of C4 plants should support growth on saline soil. However, it appears too early to generalize on a possible advantage that $\mathrm{C} 4$ plants possibly have since many other traits participate in salinity tolerance a priori.

A higher redox status of antioxidants and the coordinated increase in SOD, CAT, GPX, APX, and GR activities was suggested by Mishra et al. (2013) to serve as the major determinants of salt tolerance in Indica rice seedlings. In this study, the activity of CuZn-SOD, APX, GPX, CAT, MDHAR, DHAR, and GR increased in the salt tolerant cultivar like in salt-sensitive seedlings at moderate salinity of $7 \mathrm{dS} \mathrm{m}^{-1} \mathrm{NaCl}$. In contrast, the activity of GPX, CAT, MDHAR, DHAR, and GR decreased with higher salinity of $14 \mathrm{dS} \mathrm{m}^{-1} \mathrm{NaCl}$ in the sensitive genotype. Cultivars with distinct salt sensitivity allow exploring involved mechanisms. Pusa Basmati-1 is highly salt sensitive, while Pokkali displays moderate salt tolerance. In parallel the activity of the ROS scavenging CAT and the levels of antioxidants like ASA and GSH are increased and concomitantly the membrane damage as judged from lipid peroxidation and $\mathrm{H}_{2} \mathrm{O}_{2}$ levels are lower in Pokkali compared to Pusa Basmati-1 (Vaidyanathan et al., 2003). Transcript regulation of peroxisomal APX (HvAPX1) correlates with salt stress (Shi et al., 2001). Lin and Pu (2010) studied the involvement of ROS scavenging enzymes in tolerant and sensitive sweet potato under salinity. The activity increase of cAPX, mAPX and chlAPX 24 and $48 \mathrm{~h}$ after exposure to $450 \mathrm{mM} \mathrm{NaCl}$ was higher in the salt stresstolerant genotype than in the sensitive ones. Overall induction and maintenance of a strong antioxidant defense frequently correlates with enhanced salt tolerance.

Likewise genetic fortification of antioxidant levels has been shown to enhance salinity tolerance by decreasing the oxidative stress. Transgenic tobacco overexpressing cytosolic AtMDAR1 exhibited up to 2.1-fold higher MDAR activity and 2.2-fold higher levels of reduced AsA than non-transformed control plants and concomitantly the tolerance to salt stress was enhanced (Eltayeb et al., 2007). Likewise, transgenic Arabidopsis over-expressing rice cytosolic OsAPXa/b exhibited increased salt tolerance compared to wild-type (Lu et al., 2007). A similar improvement in salt stress tolerance was observed in transgenic tobacco expressing the AtcAPX gene (Badawi et al., 2004) or the Solanum lycopersicum tAPX (SltAPX) (Sun et al., 2010). Transgenic tobacco simultaneously expressing CuZnSOD, APX, and DHAR in the chloroplast tolerated $100 \mathrm{mM} \mathrm{NaCI}$ without developing salt-induced injury observed in wild type (Lee et al., 2007). Prashanth et al. (2008) applied salt stress to indica rice var Pusa Basmati-1 overexpressing cytosolic Cu/ZnSOD from the mangrove Avicennia marina. The heterologous expression conferred salinity stress tolerance in hydroponics and pot experiments. GhSOD1-, GhAPX1-, and GhCAT1-overexpressing cotton showed higher tolerance to salinity than WT, and the synergistic effects of GhSOD1 and GhCAT1 were suggested to provide a new strategy for enhancing salt stress tolerance (Luo et al., 2013). Overall the results from transgenic approaches are complementary to the correlative evidence at the level of regulation of enzyme activity and of transcripts amounts and support the conclusion that enhanced antioxidant activity fosters salt acclimation. Figure 3 summarizes the various antioxidant systems in chloroplast, mitochondrion and peroxisome. It also indicates the sites of the safety valves and generator systems which will be discussed next, the alternative oxidase (AOX), the plastid terminal oxidase (PTOX), the respiratory burst oxidase homolog $(\mathrm{RBOH})$ and the malate valve.

\section{ALTERNATIVE OXIDASE (AOX)}

Redox and ROS metabolism are tightly linked. Overreduction of electron transport chains enhances ROS production as discussed above. In higher plants, the respiratory electron transport chain (RET) feeds electrons to two terminal oxidases, namely cytochrome c oxidase (complex IV) for ATP synthesis and the cyanide-insensitive AOX for energy dissipation (Rogov et al., 2014). The conditional bifurcation to both pathways maintains the energy balance as well as redox homeostasis in dependence on the cellular energy demand. Drainage of electrons into the AOX pathway increases under stress (Zhang et al., 2016). Earlier the AOX capacity was demonstrated to respond to salinity in plants such as barley (Jolivet et al., 1990), soybean (Hilal et al., 1998) and carrot (Ferreira et al., 2008). Activation of AOX1a occurs via a thiol switch mechanism (Winger et al., 2007) and stimulates alternative respiration, decreases electron pressure and prevents over-reduction of the ubiquinone (UQ) pool which dampens excessive $\mathrm{O}_{2}^{\bullet-}$ and $\mathrm{H}_{2} \mathrm{O}_{2}$ generation and lowers ROS damage to plant cells under salt stress (Wang et al., 2010; Yoshida et al., 2011). In addition, AOX is involved in defining the threshold for the induction of programmed cell death (PCD) by signaling mechanism (Van Aken et al., 2009) and modulating the release of reactive nitrogen species (RNS). Release of nitric oxide (NO) in mitochondria is induced by accumulating reducing equivalents (Cvetkovska et al., 2014; Igamberdiev et al., 2014). In rice, expression of AOX1A and AOX1B in the nucleus is stimulated during saline conditions through mitochondrial retrograde regulation mediated by oxygen radicals ( $\mathrm{Li}$ et al., 2013; Voss et al., 2013). Smith et al. (2009) reported AOX activation and stimulation of alternative electron transport in response to salinity stress. This mechanism allowed for suppressing ROS generation and increased the growth rates. Lower $\mathrm{Na}^{+}$accumulation in shoots suggests a link between long distance $\mathrm{Na}^{+}$transport and tissue ROS levels. This tentative dependency offers a mechanistic framework to exploit AOX and redox homeostasis to improve the acclimation ability to salt stress.

\section{RESPIRATORY BURST OXIDASE HOMOLOGS (RBOH)}

Homologs of NADPH oxidase in plants and animals contain cytosolic FAD- and NADPH-binding domains and six 


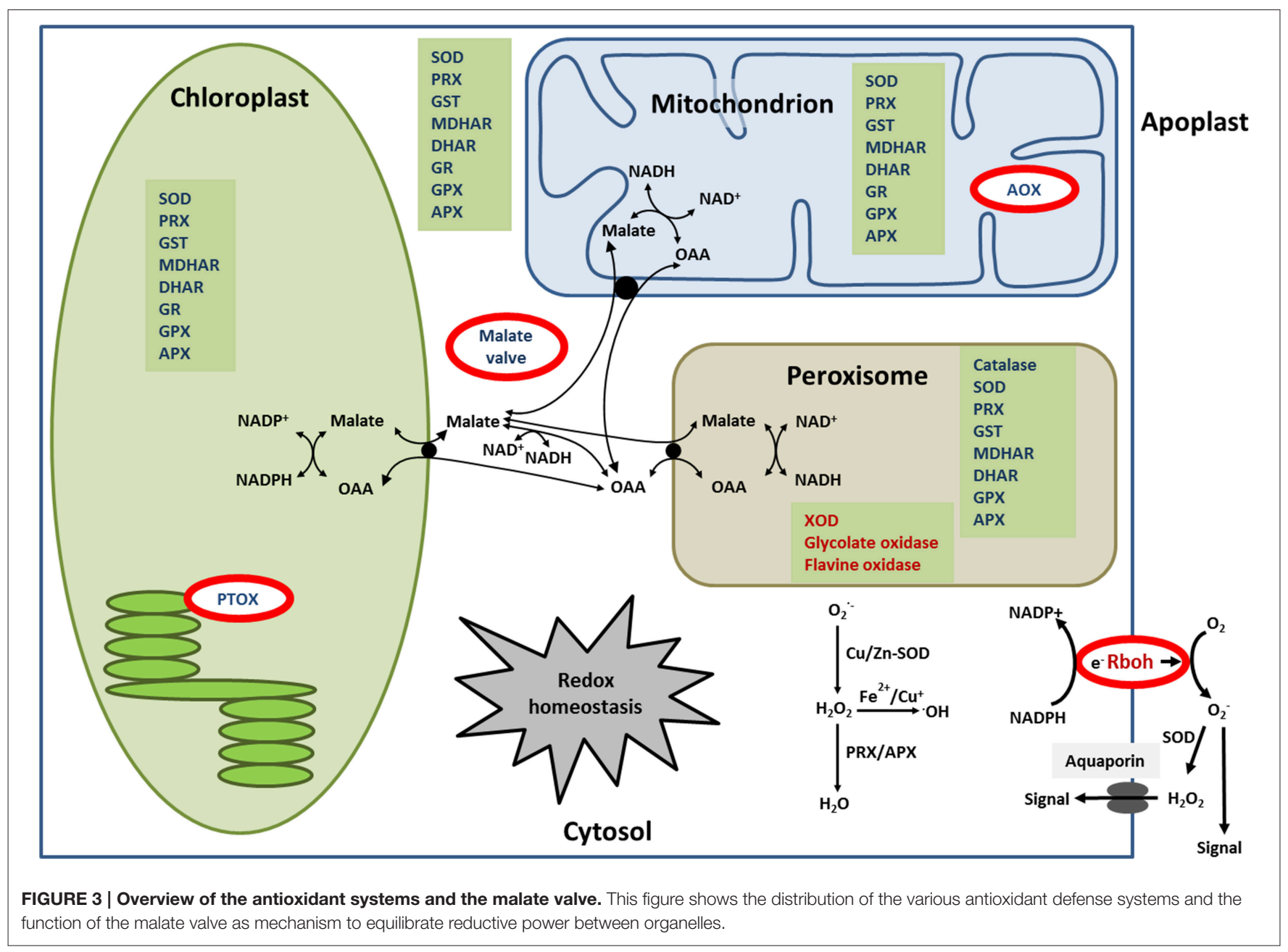

membrane-spanning helices. Two heme groups participate in the transfer of electrons from cytosolic NADPH or NADH to oxygen on the apoplastic side. This transfer produces $\mathrm{O}_{2}^{\bullet-}$ radicals in the extracellular matrix (Lambeth, 2004; Sagi and Fluhr, 2006). In plants, these enzymes are named $\mathrm{RBOH}$ and function in a plethora of processes, such as hyersensitive response to pathogens, abiotic stress tolerance, and local and systemic signaling (Torres et al., 2002; Monshausen et al., 2009). ROS released by $\mathrm{RBOH}$ act in several hormone-signaling pathways (Sagi and Fluhr, 2006).

RBOHA activity is induced by salt stress in the root elongation zone in Arabidopsis (Sagi and Fluhr, 2006). In Arabidopsis AtRBOHD and AtRBOHF are expressed in all plant organs and are the main isoforms involved in ROSdependent regulation of $\mathrm{Na}^{+} / \mathrm{K}^{+}$homeostasis under salt stress (Ma et al., 2012). AtRBOHD has also been demonstrated to mediate rapid systemic signaling triggered by multiple abiotic stresses (Miller et al., 2009) and to be required for salt acclimation signaling mediated by heme oxygenase HY1 in Arabidopsis (Xie et al., 2011). RBOHD shows the highest expression among the ten AtRBOH genes in A. thaliana (Suzuki et al., 2011) and functions in abscisic acid-dependent stomatal closure, flagellin-induced immune responses, and salt acclimation via ROS production (Torres et al., 2002; Pogány et al., 2009; Xie et al., 2011). Under salt stress RBOHD are clustered in the plasmamembrane and subjected to endocytosis and their activation facilitates the activation of redox signaling pathways and plays an important role in salt acclimation of Arabidopsis (Leshem et al., 2007; Xie et al., 2011; Hao et al., 2014).

Mild salt stress causes a rapid and transient accumulation of ROS in Arabidopsis peaking after $1 \mathrm{~h}$ followed by a second oxidative burst after about $6 \mathrm{~h}$ (Xie et al., 2011). The interpretation was that HY1 plays an important role in salt stresssignaling and that this pathway requires the participation of AtRBOHD-derived ROS from peak II. More recently, AtRBOHF was implicated in protecting shoot cells from transpirationdependent accumulation of excess $\mathrm{Na}^{+}$(Jiang et al., 2012). ROS generated by AtRBOHF have a specific role in regulating $\mathrm{Na}^{+}$ accumulation and soil-salinity tolerance (Jiang et al., 2012). Sakamoto et al. (2008) found that the expression of RBOHC/D/F genes is induced in response to salt stress in wild-type plants. The salt-responsive induction of $R B O H$ accumulation was markedly suppressed in the itn1-1 mutant. This mutant revealed 
increased tolerance to $\mathrm{NaCl}$ by affecting the ABA-mediated ROS production (Sakamoto et al., 2008). This suggest that the itn1-1, an ankyrin-repeat containing membrane protein, suppresses induction of the NADPH oxidase genes in response to salt stress, resulting in lower levels of $\mathrm{H}_{2} \mathrm{O}_{2}$, and that this may cause the salt-tolerant phenotype. The comparison of the salinity response of Arabidopsis wild type and AtrbohD/F double mutant indicates that the early $\mathrm{H}_{2} \mathrm{O}_{2}$ generation by NADPH oxidase triggers the antioxidant response in A. thaliana. The fortified antioxidant defense counteracts the subsequent ROS production and thereby mitigates the salt stress-derived injuries (Rejeb et al., 2014). According to Leshem et al. (2007), the saltinduced ROS production by NADPH oxidase in endosomes was suppressed in the phosphatidylinositol 3 kinase mutant (pi3k) and this mechanism causes a reduction in oxidative stress. In this experiment $\mathrm{RBOH}$ produces $\mathrm{O}_{2}^{\bullet-}$ which is coordinated by the phospholipid-regulated signaling pathway and takes part in signal transduction in response to salt stress (Leshem et al., 2007). RBOHs also contribute to proline accumulation in response to salt or mannitol stress (Rejeb et al., 2015b). The timing and the magnitude of $\mathrm{RBOH}$-dependent $\mathrm{O}_{2}^{\bullet-}$-generation participate in inducing the salinity acclimation response on the one hand, but also in accelerating the deleterious effect of excessive ROS accumulation leading to salinity toxicity on the other hand.

$\mathrm{RBOH}$-dependent ROS triggers signal transduction pathways and mediates local and systemic signaling (Miller et al., 2009; Marino et al., 2012). The initial $\mathrm{Ca}^{2+}$-influx through plasma membrane ion channels and the $\mathrm{RBOH}$-mediated production of ROS are synergistically activated by the binding of $\mathrm{Ca}^{2+}$ to EFhand motifs as well as $\mathrm{Ca}^{2+}$-dependent phosphorylation. Both mechanisms participate in regulating acclimation to salinity in plants including halophytes (Kurusu et al., 2015). RBOHs are central players in the $\mathrm{Ca}^{2+}$-ROS signaling network triggered by their phosphorylation during stress adaptation (Kimura et al., 2012; Gilroy et al., 2014). This $\mathrm{Ca}^{2+}$ - and ROS-dependent signaling network regulates downstream events such as the $\mathrm{Ca}^{2+}$-dependent activation of the $\mathrm{Na}^{+} / \mathrm{H}^{+}$-exchangers SOS 1 and $\mathrm{NHX} 1, \mathrm{Na}^{+}$efflux from the cytosol, xylem loading of $\mathrm{Na}^{+}$, $\mathrm{Na}^{+}$exclusion from leaves, induction of osmolyte synthesis and osmo-protective proteins, and overall the maintenance of cytosolic ion balance (Reguera et al., 2014). Work with atrbohD/F double mutants revealed that ROS are rate-limiting second messengers in ABA signaling. AtRBOHD/F function in ABA signal transduction in guard cell (Kwak et al., 2003). Following ABA perception in guard cells, active SnRK2 kinases such as OST1 (OPEN STOMATA 1) phosphorylate RBOHF and thereby stimulate ROS accumulation which in turn activates two MAPKs and regulates ABA-mediated stomatal closure (Danquah et al., 2014). RBOH-dependent ROS have been detected in vesicles in response to salt stress or during abscisic acid (ABA)-induced stomatal closure (Leshem et al., 2007). The different signaling mechanisms in $\mathrm{RBOH}$ activity control and the direct and indirect involvement in multiple downstream, processes characterize $\mathrm{RBOH}$ as a signaling hub for salinity acclimation.

\section{NADP-DEPENDENT MALATE DEHYDROGENASE (NADP-MDH) AND THE MALATE VALVE}

$\mathrm{O}_{2}^{\bullet-}$ is generated in the PET by transfer of electrons from ferredoxin or reduced plastoquinone to $\mathrm{O}_{2}$, particularly if $\mathrm{NADP}^{+}$or other terminal electron acceptors are unavailable. Likewise strong $\mathrm{NADH}$ feeding into the respiratory chain eases $\mathrm{O}_{2}^{\bullet-}$ generation as long as AOS is not activated. Thus, reoxidation of NADPH to $\mathrm{NADP}^{+}$is important for balancing the ATP/NAD $(\mathrm{P}) \mathrm{H}$ ratio and maintaining redox homeostasis. The photosynthesizing chloroplast employs diverse mechanisms to balance the rates of ATP and NADPH generation, e.g., by activating cyclic electron flow (CEF) which is under control of redox stimuli (Strand et al., 2015). Naturally such mechanisms do not allow for drainage of excess electrons if metabolic consumption is inhibited. Under such conditions activation of the malate-oxaloacetate (OAA) shuttle allows for transfer of reducing equivalents between cell compartments, e.g., under stress condition of plant (Heber, 1974; Taniguchi and Miyake, 2012; Figure 3). Another $\mathrm{NADP}^{+}$-generating mechanism is chloroplastic GR which reduces GSSG released in the water-water cycle. Excess electrons from photosynthetic electron transport are used by TRX-regulated NADP-dependent malate dehydrogenase $(\mathrm{MDH})$ to reduce $\mathrm{OAA}$ to malate, thus regenerating the electron acceptor $\mathrm{NADP}^{+}$(Scheibe et al., 2005). The resulting malate is subsequently translocated to the cytosol via the malate-OAA shuttle, where the interconversion of malate to $\mathrm{OAA}$ with concomitant reduction of $\mathrm{NAD}^{+}$to $\mathrm{NADH}$ is catalyzed by the cytosolic NAD-MDH (Hara et al., 2006). The $\mathrm{NADH}$ is fed into the RET. This allows for maintenance of chloroplast redox homeostasis and plays an important role in the short-term adjustment of the $\mathrm{NADP}(\mathrm{H})$ redox state also in response to salinity stress (Scheibe et al., 2005). In line with this scenario, Cushman (1993) measured a more than twofold increase of chloroplast NADP-MDH transcript level in leaves of Mesembryanthemum crystallinum under salt stress. In a recent study, Gawronska et al. (2013) described a set of protective strategies which accompany acclimation to salinity in the halophytic species $M$. crystallinum. The malate valve appears to be of prime importance. Salinity stress increases activities of NAD-MDH in whole tissue extract, and specifically mitochondrial NAD-MDH and chloroplast NADP-MDH in salt tolerant rice cr CSR-1 and CSR-3 whereas the activities were inhibited in salt sensitive cultivars (Kumar et al., 2000). Apparently the malate valve-dependent redox balance constitutes an important mechanism in salt acclimation.

\section{PLASTID TERMINAL OXIDASE (PTOX)}

The plastid terminal oxidase (PTOX) is a nucleus-encoded plastid-located plastoquinone (PQ)- $\mathrm{O}_{2}$ oxidoreductase (plastoquinol oxidase) which transfers electrons from $\mathrm{PQ}$ to $\mathrm{O}_{2}$ and forms $\mathrm{H}_{2} \mathrm{O}$ (Carol et al., 1999). It represents the key component of an alternative electron pathway which involves 


\section{Damage: Deregulation, decreased fitness, yield loss, cell death}

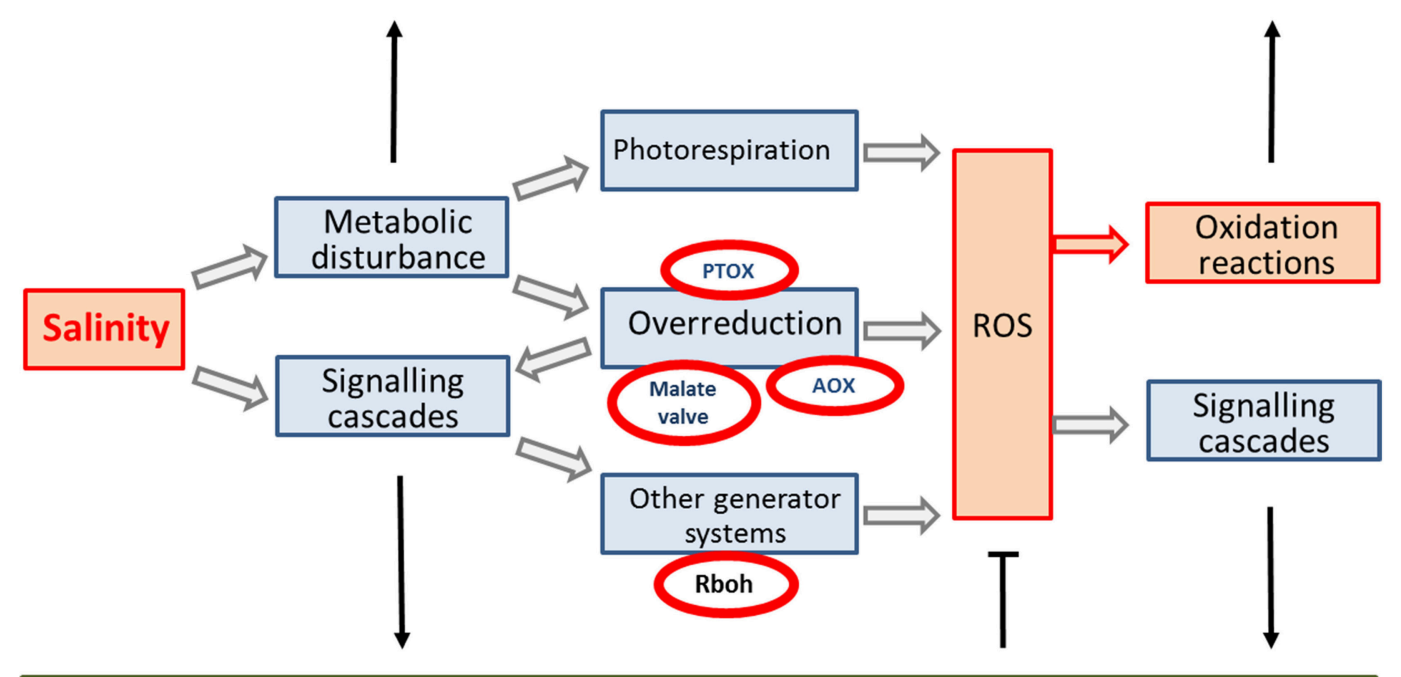

Acclimation: $\mathrm{Na} / \mathrm{K}$ - and osmotic homeostasis, osmolytes, antioxidant defence

FIGURE 4 | Circuitry of redox and ROS-related events in salinity stress response. Salinity stress causes metabolic imbalances and activates signaling pathways. The metabolic imbalances increase the ROS generation e.g., by enhanced photorespiration or cause overreduction of PET and RET as described in the review. The latter is modulated by AOX, PTOX and malate valve. Signaling activates RBOH. Accumulating ROS either cause excessive oxidation reactions leading to damage or via redox- and ROS-dependent signaling and regulation allow for proper acclimation.

the reduction of $\mathrm{PQ}$ by $\mathrm{NAD}(\mathrm{P}) \mathrm{H}$ dehydrogenase $(\mathrm{NDH})$ and the oxidation of reduced PQ by PTOX (Peltier and Cournac, 2002). PTOX is involved in chloroplast development and is suggested to act as safety valve to prevent the over-reduction of the photosynthetic machinery under stress conditions (Carol et al., 1999). However, additional features of PTOX have questioned the safety valve function owing to its ability to produce ROS under stress (Heyno et al., 2009; Feilke et al., 2014; Yu et al., 2014). When the PQ pool is highly reduced, PTOX itself produces superoxide $\left(\mathrm{O}_{2}^{\bullet-}\right)$ in a side reaction, triggering retrograde signaling to the cytosol and altering expression of response genes needed for acclimation to the environment ( $\mathrm{Yu}$ et al., 2014; Krieger-Liszkay and Feilke, 2016). Overexpression of PTOX in A. thaliana did not protect against light-induced photodamage (Rosso et al., 2006) which appears contradictory to a protective function of PTOX. Under excess light PTOX overexpressors generate $\mathrm{O}_{2}^{\bullet-}$. If this $\mathrm{O}_{2}^{\bullet-}$ is efficiently detoxified by the antioxidant system, then even this mechanism may act as a safety valve (Heyno et al., 2009). If the antioxidant system is overwhelmed then PTOX-generated $\mathrm{O}_{2}^{\bullet-}$ would enhance damage formation. Overall, the function of PTOX appears to be Januslike. PTOX-dependent ROS may damage the photosynthetic apparatus or contribute to its protection and regulation.

$\mathrm{Up}$ to $10 \%$ of the photochemically produced $\mathrm{O}_{2}$ in Haematococcus pluvialis was consumed by PTOX via the astaxanthin biosynthesis pathway. This pathway could lower the oxygen partial pressure and thereby reduce ROS release in the alga cell (Li et al., 2008). PTOX protects PSII by moving the site of ROS production from the appressed membranes with the majority of PSII to the nonappressed membranes where PTOX is located (Joët et al., 2002). In stressed plants, PTOX plays a regulatory role in carotenoid biosynthesis and in PQ oxidase activity in chlororespiration to re-oxidize reduced PQ (Bennoun, 1982; Kuntz, 2004; Campos et al., 2015). PTOX also controls the stromal redox poise (Trouillard et al., 2012). The abundance of PTOX is positively correlated with the intensity of salinity stress (Ivanov et al., 2012; Nawrocki et al., 2015). PTOX levels increase in salt stressed plants. PTOXdependent electron drainage accounted for up to $30 \%$ of total PSII electron flow which provides strong evidence for its role as safety valve relative to photorespiration (Stepien and Johnson, 2009). Intensive $\mathrm{H}_{2} \mathrm{O}_{2}$ generation in photorespiration stimulated the activity of PTOX. This regulation seems to anticipate and subsequently counteract the effects of aggravating salinity stress. In a converse manner, inhibition of PTOX stimulated the $\mathrm{H}_{2} \mathrm{O}_{2}$ formation which might be important as signaling cue to initiate acclimation of halophytic Thellungiella plants (Wiciarza et al., 2015). PTOX attaches to the thylakoids at alkaline $\mathrm{pH}$. This led to the suggestion that PTOX senses excessive alkalization of the stroma, subsequently attaches to the thylakoids and facilitates reoxidation of the PQ pool. By this mechanism overreduction of the photosynthetic electron 
transport is avoided and ROS generation decreased (Feilke et al., 2016).

\section{OTHER MECHANISMS OF ELECTRON DRAINAGE UNDER SALINITY}

The accumulation of organic osmolytes, such as proline, glycine betaine, sugar alcohols, polyamines, and proteins e.g., from the late embryogenesis abundant (LEA) superfamily, in plasmatic compartments balances the osmotic potentials and maintains the low intracellular water potential of plants. Due to their compatible nature, these osmolytes counteract the harmful effects of ionic and osmotic stress (Verslues et al., 2006). Proline plays a crucial role in osmotic adjustment and acts as ROS scavenger, redox buffer, molecular chaperone which stabilizes proteins and membrane structures under stress (Matysik et al., 2002; Ashraf and Foolad, 2007). Proline synthesis via the glutamate pathway consumes 2 mol NADPH per mol proline and thus drains electrons from the chloroplast and buffers the cell reduction state (Hare and Cress, 1997). Accumulation of proline in leaves upon salt stress allows for continued carbon reduction and counteracts photoinhibition and excess ROS production. In the mitochondria proline is catabolized and the reducing power can be dissipated by RET coupled to AOX bypassing complex III and IV. Analyses of transcriptional regulation and knockout mutants indicate that the Arabidopsis $\Delta 1$-pyrroline-5-carboxylate synthetase1 (P5CS1) genes, the controlling step of proline synthesis, have clearly distinct functions. P5CS1 is strongly induced under high salinity (Szekely et al., 2008). Consistent with the upregulation of AtP5CS1, p5cs1 knockout mutants have greatly reduced proline levels during salt stress, resulting in reduced growth and altered ROS levels, suggesting that they are hypersensitive to salt (Szekely et al., 2008). Similar to proline, glycine betaine is an organic osmolyte synthesized by several plant families to balance the osmotic potential of intracellular compartments (Chen and Murata, 2011) under salinity. The plant pathway of synthesis consumes two electrons as net balance (Sakamoto and Murata, 2000). Activation of antioxidant mechanisms by proline and glycine betaine during salinity has been studied using tobacco bright yellow-2 suspension cultured cells (Hoque et al., 2007; Banu et al., 2009). Salinity significantly decreased the levels of reduced ascorbic acid and GSH, and the activity of water-water-cycle enzymes, and exogenous application of proline or glycine betaine increased the activity of these enzymes (Hoque et al., 2007). These results suggest a role of proline and glycine betaine in the regulation of antioxidant enzymes during salinity.

The last example of electron drainage with major significance for salinity is the pathway of photorespiration. Salinity-induced stomatal closure in moderately salt-stressed leaves leads to a drop in intercellular $\mathrm{CO}_{2}$ concentration, increased oxygenation reaction of ribulose-1,5-bisphosphate carboxylase/oxygenase, enhanced formation of photorespiratory metabolites such as phosphoglycolate, glycine and serine, and concomitant increase in $\mathrm{H}_{2} \mathrm{O}_{2}$ release in the peroxisomes, and $\mathrm{CO}_{2}$ and NADH in the mitochondrion (Di Martino et al., 1999). The maintenance of electron transport by photorespiration in $\mathrm{CO}_{2}$-free air corroborates the significance of photorespiration in salt-stressed leaves (Di Martino et al., 1999). Sustained rates of electron transport due to photorespiration and the formation of zeaxanthin during salt stress probably mitigate photoinhibitory damage (Sharma and Hall, 1992). The xanthophyll cycle is known as dynamic photoinhibition process that prevents overexcitation of the photosynthetic apparatus by dissipation of excess excitation energy (Krinsky, 1989; Niyogi et al., 1998). But, photorespiration also releases $\mathrm{H}_{2} \mathrm{O}_{2}$ in the peroxisomes as outlined above. The antioxidant system in the peroxisome efficiently detoxifies the photorespiratory $\mathrm{H}_{2} \mathrm{O}_{2}$. Jiménez et al. (1997) reported the presence of APX and MDHAR in peroxisomal membranes and argued that the membrane-bound antioxidant enzymes protect against $\mathrm{H}_{2} \mathrm{O}_{2}$ leaking out of peroxisomes. The photorespiratory $\mathrm{NADH}$ can be used in complex IV dependent RET for ATP synthesis or dissipated by AOX. This section on alternative drainage mechanisms only provides examples of involved pathways and cannot provide a comprehensive view.

\section{CONCLUSIONS AND OUTLOOK}

Maintenance of redox homeostasis is central to plant survival under salinity stress. Successful acclimation to saline growth conditions involves control of generation systems and tuning of antioxidant mechanisms. Under normal growth conditions generation and scavenging of ROS, and repair of damage are balanced. Salinity interferes with metabolism by ionic and osmotic effects and alters the redox and ROS state of the cell (Figure 4). This review demonstrates the flexible adjustment of each of the steps in response to salinity. It is striking that the described redox and ROS-related mechanisms of defense under salinity fit to the defense repertoire under other stresses such as photooxidative conditions. The specificity comes from the qualitative and quantitative use of stressspecific isoforms as discussed above. The principle differences between salt-sensitive and -tolerant genotypes includes specific symptomatic differences in redox and ROS generation. The central mechanisms realizing salt acclimation within the given tolerance range is selective short and long distance ion transport, safe ion compartmentation, synthesis of compatible solutes, and adjustment of osmotic homeostasis. As long as these mechanisms realize effective ion detoxification, deregulation of redox and ROS homeostasis is a minor component in stress acclimation. This changes if the salinity stress approaches the tolerance limits or during transition periods. Then the ultimate reason for decreased growth, reduced fitness and finally cell death are alteration in metabolism and excessive ROS accumulation (Figure 4). Some environmental conditions enhance salinity stress like periodical flooding with sea water, drought in saline environment or irrigation with saline water. The various mechanisms of dissipation of excess reducing power are mutually dependent. A. thaliana lacking chloroplast malate dehydrogenase are phenotypically inconspicuous (Hebbelmann et al., 2012). Proline synthesis, increased photorespiration and activation of 
thiol peroxidase appear to compensate for the deficiency in NADP-MDH in high light treated nadph-mdh plants. This example shows the flexibility and partial redundancy of processes to control ROS release due to excessively accumulating reducing power and control of antioxidant defense which also contributes to salt stress acclimation. As long as the homeostasis mechanisms are functional and control the metabolic imbalances and keep ROS and redox deviations under control, small changes in redoxand ROS signatures are used to control gene expression, protein synthesis, metabolic activities and enable acclimation.

\section{REFERENCES}

Abogadallah, G. M., Serag, M. M., and Quick, W. P. (2009). Fine and coarse regulation of reactive oxygen species in the salt tolerant mutants of barnyard grass and their wildtype parents under salt stress. Physiol. Plant. 138, 60-73. doi: 10.1111/j.1399-3054.2009.01297.x

Acosta-Motos, J. R., Diaz-Vivancos, P., Àlvarez, S., Fernández-García, N., SanchezBlanco, M. J., and Hernández, J. A. (2015). Physiological and biochemical mechanisms of the ornamental Eugenia myrtifolia L. plants for coping with $\mathrm{NaCl}$ stress and recovery. Planta 242, 829-846. doi: 10.1007/s00425-015-2315-3

Andreyev, A. Y., Kushnareva, Y. E., and Starkov, A. A. (2005). Mitochondrial metabolism of reactive oxygen species. Biochemistry 70, 200-214. doi: 10.1007/s10541-005-0102-7

Aono, M., Kubo, A., Saji, H., Tanaka, K., and Kondo, N. (1993). Enhanced tolerance to photooxidative stress of transgenic Nicotiana tabacum with high chloroplastic glutathione reductase activity. Plant Cell Physiol. 34, 129-135.

Asada, K. (1992). Ascorbate peroxidase - a hydrogen scavenging enzyme in plants. Physiol. Plant. 85, 235-241. doi: 10.1111/j.1399-3054.1992.tb04728.x

Ashraf, M., and Foolad, M. R. (2007). Roles of glycine betaine and proline in improving plant abiotic stress resistance. Environ. Exp. Bot. 59, 206-216. doi: 10.1016/j.envexpbot.2005.12.006

Azevedo Neto, A. D., Gomes Filho, E., and Prisco, J. T. (2008). "Salinity and oxidative Stress," in Abiotic stress and Plant Responses, eds N. A. Khan and S. Singh (New Delhi: IK International), 58-82.

Badawi, G. H., Kawano, N., Yamauchi, Y., Shimada, E., Sasaki, R., Kubo, A., et al. (2004). Over-expression of ascorbate peroxidase in tobacco chloroplasts enhances the tolerance to salt stress and water deficit. Physiol. Plant. 121, 231-238. doi: 10.1111/j.0031-9317.2004.00308.x

Baker, A., and Graham, A. I. (2002). Plant Peroxisomes: Biochemistry, Cell Biology and Biotechnological Applications. Dordrecht: Kluwer Academic Publishers. doi: 10.1007/978-94-015-9858-3

Banu, N. A., Hoque, A., Watanabe-Sugimoto, M., Matsuoka, K., Nakamura, Y., Shimoishi, Y., et al. (2009). Proline and glycinebetaine induce antioxidant defense gene expression and suppress cell death in cultured tobacco cells under salt stress. J. Plant Physiol. 166, 146-156. doi: 10.1016/j.jplph.2008.03.002

Baxter, A., Mittler, R., and Suzuki, N. (2014). ROS as key players in plant stress signalling. J. Exp. Bot. 65, 1229-1240. doi: 10.1093/jxb/ert375

Bennoun, P. (1982). Evidence for a respiratory chain in the chloroplast. Proc. Natl. Acad. Sci. U.S.A. 79, 4352-4356. doi: 10.1073/pnas.79.14.4352

Borzouei, A., Kafi, M., Akbari-Ghogdi, E., and Mousavi-Shalmani (2012). M. Long term salinity stress in relation to lipid peroxidation, super oxide dismutase activity and proline content of saltsensitive and salt-tolerant wheat cultivars. Chilean J. Agril. Res. 72, 476-482. doi: 10.4067/S0718-58392012000400003

Campos, M. D., Campos, C., Cardoso, H. G., Simon, P. W., Oliveira, M., Nogales, A., et al. (2015). Isolation and characterization of plastid terminal oxidase gene from carrot and its relation to carotenoid accumulation. Plant Gene 5, 13-21. doi: 10.1016/j.plgene.2015.10.005

Carol, P., Stevenson, D., Bisanza, C., Breitenbachc, J., Sandmannc, G., Machea, R., et al. (1999). Mutations in the Arabidopsis gene IMMUTANS cause a variegated phenotype by inactivating a chloroplast terminal oxidase associated with phytoene desaturation. Plant Cell 11, 57-68. doi: 10.1105/tpc.11.1.57

Cavalcanti, F. R., Oliveira, J. T. A., Martins-Miranda, A. S., Viégas, R. A., and Silveira, J. A. G. (2004). Superoxide dismutase, catalase and peroxidase activities do not confer protection against oxidative damage in salt-stressed

\section{AUTHOR CONTRIBUTIONS}

All authors listed, have made substantial, direct and intellectual contribution to the work, and approved it for publication.

\section{ACKNOWLEDGMENTS}

$\mathrm{MH}$ acknowledges support by the German Academic Exchange Service (DAAD). The own work was funded by the Deutsche Forschungsgemeinschaft.

cowpea leaves. New Phytol. 163, 563-571. doi: 10.1111/j.1469-8137.2004. 01139.x

Chen, T. H., and Murata, N. (2011). Glycinebetaine protects plants against abiotic stress: mechanisms and biotechnological applications. Plant Cell Environ. 34, 1-20. doi: 10.1111/j.1365-3040.2010.02232.x

Cleland, R. E., and Grace, S. C. (1999). Voltammetric detection of superoxide production by photosystem II. FEBS Lett. 457, 348-352. doi: 10.1016/S00145793(99)01067-4

Cona, A., Rea, G., Angelini, R., Federico, R., and Tavladoraki, P. (2006). Functions of amine oxidases in plant development and defence. Trend. Plant Sci. 11, 80-88. doi: 10.1016/j.tplants.2005.12.009

Considine, M. J., Holtzapffel, R. C., Day, D. A., Whelan, J., and Millar, A. H. (2002). Molecular distinction between alternative oxidase from monocots and dicots. Plant Physiol. 129, 949-953. doi: 10.1104/pp.004150

Cushman, J. C. (1993). Molecular cloning and expression of chloroplast NADPmalate dehydrogenase during Crassulacean acid metabolism induction by salt stress. Photosynth. Res. 35, 15-27. doi: 10.1007/BF02185408

Cushman, J. C., and Bohnert, H. J. (1997). Molecular genetics of Crassulacean acid metabolism. Plant Physiol. 113, 667-676.

Cvetkovska, M., Dahal, K., Alber, N. A., Jin, C., Cheung, M., and Vanlerberghe, G. C. (2014). Knockdown of mitochondrial alternative oxidase induces the 'stress state' of signaling molecule pools in Nicotiana tabacum, with implications for stomatal function. New Phytol. 203, 449-461. doi: 10.1111/nph.12773

Dai, Z., Ku, M. S. B., and Edwards, G. E. (1996). Oxygen sensitivity of photosynthesis and photorespiration in different photosynthetic types in the genus Flaveria. Planta 198, 563-571. doi: 10.1007/BF00262643

Danquah, A., de Zelicourt, A., Colcombet, J., and Hirt, H. (2014). The role of ABA and MAPK signaling pathways in plant abiotic stress responses. Biotech. Adv. 32, 40-52. doi: 10.1016/j.biotechadv.2013.09.006

Devi, M. T., and Raghavendra, A. S. (1993). Photorespiration in C3-C4 intermediate species of Alternanthera and Parthenium: reduced ammonia production and increased capacity of $\mathrm{CO} 2$ refixation in the light. Photosynth. Res. 38, 177-184. doi: 10.1007/BF00146417

Dietz, K. J. (2008). Redox signal integration: From stimulus to networks and genes. Physiol. Plant. 133, 459-468. doi: 10.1111/j.1399-3054.2008.01120.x

Dietz, K. J. (2016). Thiol-based peroxidases and ascorbate peroxidases: why plants rely on multiple peroxidase systems in the photosynthesizing chloroplast? Mol Cells 39, 20-25. doi: 10.14348/molcells.2016.2324

Dietz, K. J., Jacob, S., Oelze, M. L., Laxa, M., Tognetti, V., De Miranda, S. M., et al. (2006). The function of peroxiredoxins in plant organelle redox metabolism. J. Exp. Bot. 57, 1697-1709. doi: 10.1093/jxb/erj160

Di Martino, C., Delene, S., Alvino, A., and Loreto, F. (1999). Photorespiration rate in spinach leaves under moderate $\mathrm{NaCl}$ stress. Photosynthesis 36, 233-242. doi: 10.1023/A:1007099627285

Ellouzi, H., Ben Hamed, K., Cela, J., Munne-Bosch, S., and Abdelly, C. (2011). Early effects of salt stress on the physiological and oxidative status of Cakile maritima (halophyte) and Arabidopsis thaliana (glycophyte). Physiol. Plant. 142, 128-143. doi: 10.1111/j.1399-3054.2011.01450.x

Elstner, E. F. (1991). "Mechanisms of oxygen activation in different compartments of plant cells," in Active Oxygen/Oxidative Stress and Plant Metabolism, eds E. J. Pell and K. L. Steffen (Rockville, MD: American Society of Plant Physiologists), $13-25$.

Eltayeb, A. E., Kawano, N., Badawi, G. H., Kaminaka, H., Sanekata, T., Shibahara, T., et al. (2007). Overexpression of monodehydroascorbate reductase in 
transgenic tobacco confers enhanced tolerance to ozone, salt and polyethylene glycol stresses. Planta 225, 1255-1264. doi: 10.1007/s00425-006-0417-7

Feilke, K., Streb, P., Cornic, G., Perreau, F., Kruk, J., and Krieger-Liszkay, A. (2016). Effect of Chlamydomonas plastid terminal oxidase 1 expressed in tobacco on photosynthetic electron transfer. Plant J. 85, 219-228 doi: 10.1111/tpj.13101

Feilke, K., Yu, Q., Beyer, P., Setif, P., and Krieger-Liszkay, A. (2014). In vitro analysis of the plastid terminal oxidase in photosynthetic electron transport. Biochim. Biophys. Acta 1837, 1-30. doi: 10.1016/j.bbabio.2014.07.016

Ferreira, A. L., Arrabaca, J. D., Vaz-Pinto, V., and Lima-Costa, M. E. (2008). Induction of alternative oxidase chain under salt stress conditions. Biol. Plant. 52, 66-71. doi: 10.1007/s10535-008-0009-4

Flowers, T. J., and Colmer, T. D. (2008). Salinity tolerance in halophytes. New Phytol. 179, 945-963. doi: 10.1111/j.1469-8137.2008.02531.x

Foyer, C. H., Souriau, N., Perret, S., Lelandais, M., Kunert, K. J., Pruvost, C., et al. (1995). Overexpression of glutathione reductase but not glutathione synthetase leads to increases in antioxidant capacity and resistance to photoinhibition in poplar trees. Plant Physiol. 109, 1047-1057. doi: 10.1104/pp.109.3.1047

Fry, I. V., Huflejt, M., Erber, W. W. A., Peschek, G. A., and Packer, L. (1986). The role of respiration during adaptation of the freshwater cyanobacterium Synechococcus 6311 to salinity. Arch. Biochem. Biophys. 244, 686-691. doi: 10.1016/0003-9861(86)90637-5

Gawronska, K., Romanowska, E., Miszalski, Z., and Niewiadomska, E. (2013). Limitation of C3-CAM shift in the common ice plant under high irradiance. J. Plant Physiol. 170, 129-135. doi: 10.1016/j.jplph.2012.09.019

Geilfus, C. M., Mithöfer, A., Ludwig-Müller, J., Zörb, C., and Muehling, K. H. (2015). Chloride-inducible transient apoplastic alkalinizations induce stomata closure by controlling abscisic acid distribution between leaf apoplast and guard cells in salt-stressed Vicia faba. New Phytol. 208, 803-816. doi: 10.1111/nph.13507

Ghannoum, O. (2009). C4 photosynthesis and water stress. Ann. Bot. 103, 635-644. doi: $10.1093 / \mathrm{aob} / \mathrm{mcn} 093$

Gill, S. S., and Tuteja, N. (2010). Reactive oxygen species and antioxidant machinery in abiotic stress tolerance in crop plants. Plant Physiol. Biochem. 48, 909-930. doi: 10.1016/j.plaphy.2010.08.016

Gilroy, S., Suzuki, N., Miller, G., Choi, W. G., Toyota, M., Devireddy, A. R., et al. (2014). A tidal wave of signals: calcium and ROS at the forefront of rapid systemic signaling. Trends Plant Sci. 19, 623-630. doi: 10.1016/j.tplants.2014.06.013

Gross, G. G. (1977). Cell wall-bound malate dehydrogenase from horseradish. Phytochemistry 16, 319-321. doi: 10.1016/0031-9422(77)80055-1

Gupta, A. S., Heinen, J. L., Holaday, A. S., Burke, J. J., and Allen, R. D. (1993). Increased resistance to oxidative stress in transgenic plants that overexpress chloroplastic $\mathrm{Cu} / \mathrm{Zn}$ superoxide dismutase. Proc. Natl. Acad. Sci. U.S.A. 90, 1629-1633. doi: 10.1073/pnas.90.4.1629

Habib, S. H., Kausar, H., and Saud, H. M. (2016). Plant growthpromoting Rhizobacteria enhance salinity stress tolerance in Okra through ROS-scavenging enzymes. Biomed. Res. Int. 2016, 6284547. doi: $10.1155 / 2016 / 6284547$

Hao, H., Fan, L., Chen,T., Li, R., Li, X., He, Q., et al. (2014). Clathrin and membrane microdomains cooperatively regulate RbohD dynamics and activity in Arabidopsis. Plant Cell 26, 1729-1745. doi: 10.1105/tpc.113.122358

Hara, S., Motohashi, K., Arisaka, F., Romano, P. G., Arisaka, F., Romano, P. G. N., et al. (2006). Thioredoxin-h1 reduces and reactivates the oxidized cytosolic malate dehydrogenase dimer in higher plants. J. Biol. Chem. 281, 32065-32071. doi: 10.1074/jbc.M605784200

Hare, P. D., and Cress, W. A. (1997). Metabolic implications of stressinduced proline accumulation in plants. Plant Gro. Reg. 21, 79-102. doi: 10.1023/A:1005703923347

Hebbelmann, I., Selinski, J., Wehmeyer, C., Goss, T., Voss, I., Mulo, P., et al. (2012). Multiple strategies to prevent oxidative stress in Arabidopsis plants lacking the malate valve enzyme NADP-malate dehydrogenase. J. Exp. Bot. 63, 1445-1459. doi: $10.1093 /$ jxb/err386

Heber, U. (1974). Metabolite exchange between chloroplasts and cytoplasm. Annu. Rev. Plant Physiol. 25, 393-421. doi: 10.1146/annurev.pp.25.060174.002141

Hernández, J. A., Ferrer, M. A., Jimenez, A., Barcelo, A. R., and Sevilla, F. (2001). Antioxidant systems and $\mathrm{O}_{2}^{\bullet-} / \mathrm{H}_{2} \mathrm{O}_{2}$ production in the apoplast of pea leaves. Its relation with salt-induced necrotic lesions in minor veins. Plant Physiol. 127, 817-831. doi: 10.1104/pp.010188
Heyno, E., Gross, C. M., Laureau, C., Culcasi, M., Pietri, S., and KriegerLiszkay, A. (2009). Plastid alternative oxidase (PTOX) promotes oxidative stress when overexpressed in tobacco. J. Biol. Chem. 284, 31174-31180. doi: 10.1074/jbc.M109.021667

Heyno, E., Mary, V., Schopfer, P., and Krieger-Liszkay (2011). Oxygen activation at the plasma membrane: relation between superoxide and hydroxyl radical production by isolated membranes. Planta 234, 35-45. doi: 10.1007/s00425011-1379-y

Hilal, M., Zenoff, A. M., Ponessa, G., Moreno, H., and Massa, E. M. (1998). Saline stress alters the temporal patterns of xylem differentiation and alternative oxidase expression in developing soybean roots. Plant Physiol. 117, 695-701. doi: 10.1104/pp.117.2.695

Hoque, M. A., Banu, M. N., Okuma, E., Amako, K., Nakamura, Y., Shimoishi, Y., et al. (2007). Exogenous proline and glycinebetaine increase $\mathrm{NaCl}$ induced ascorbate-glutathione cycle enzyme activities, and proline improves salt tolerance more than glycinebetaine in tobacco bright yellow-2 suspensioncultured cells. J. Plant Physiol. 164, 1457-1468. doi: 10.1016/j.jplph.2006.10.004

Horie, T., and Schroeder, J. I. (2004). Sodium transporters in plants. Diverse genes and physiological functions. Plant Physiol. 136, 2457-2462. doi: $10.1104 / \mathrm{pp} .104 .046664$

Hossain, M. A., Ismail, M. R., Uddin, M. K., Islam, M. Z., and Ashrafuzzaman, M. (2013). Efficacy of ascorbate-glutathione cycle for scavenging $\mathrm{H} 2 \mathrm{O} 2$ in two contrasting rice genotypes during salinity stress. Aust. J. Crop Sci. 7, 1801-1808. Available online at: https://www.researchgate.net/publication/281711260

Igamberdiev, A. U., Ratcliffe, R. G., and Gupta, K. J. (2014). Plant mitochondria: source and target for nitric oxide. Mitochondrion 19, 329-333. doi: 10.1016/j.mito.2014.02.003

Inan, G., Zhang, Q., Li, P., Wang, Z., Cao, Z., Zhang, H., et al. (2004). Salt cress. A halophyte and cryophyte Arabidopsis relative model system and its applicability to molecular genetic analyses of growth and development of extremophiles. Plant Physiol. 135, 1718-1737. doi: 10.1104/pp.104.041723

Ivanov, A. G., Rosso, D., Savitch, L. V., Stachula, P., Rosembert, M., et al. (2012). Implications of alternative electron sinks in increased resistance of PSII and PSI photochemistry to high light stress in cold acclimated Arabidopsis thaliana. Photosynth. Res. 113, 191-206. doi: 10.1007/s11120-012-9769-y

Jaleel, C. A., Riadh, K., Gopi, R., Manivannan, P., Inès, J., Al-Juburi, H. J., et al. (2009). Antioxidant defense responses: physiological plasticity in higher plants under abiotic constraints. Acta Physiol. Planta 31, 427-436. doi: 10.1007/s11738-009-0275-6

Jiang, C., Belfield, E. J., Mithani, A., Visscher, A., Ragoussis, J., Mott, R., et al. (2012). ROS-mediated vascular homeostatic control of root-toshoot soil Na delivery in Arabidopsis. EMBO J. 31, 4359. doi: 10.1038/emboj.2012.273

Jiménez, A., Hernández, J. A., del Río, L. A., and Sevilla, F. (1997). Evidence for the presence of the Ascorbate-Glutathione cycle in Mitochondria and Peroxisomes of Pea leaves. Plant Physiol. 114, 275-284.

Joët, T., Genty, B., Josse, E. M., Kuntz, M., Cournac, L., and Peltier, G. (2002). Involvement of a plastid terminal oxidase in plastoquinone oxidation as enhanced by expression of the Arabidopsis thaliana enzyme in tobacco. J. Biol. Chem. 277, 31623-31630. doi: 10.1074/jbc.M203538200

Jolivet, Y., Pireaux, J. C., and Dizengremel, P. (1990). Changes in properties of barley leaf mitochondria isolated from NaCl-treated plants. Plant Physiol. 94, 641-646. doi: 10.1104/pp.94.2.641

Josse, E. M., Alcaraz,J. P., Laboure, A. M., and Kuntz, M. (2003). In vitro characterization of a plastid terminal oxidase (PTOX). Eur. J. Biochem. 270, 3787-3794. doi: 10.1046/j.1432-1033.2003.03766.x

Keller, T., Damude, H. G., Werner, D., Doerner, P., Dixon, R. A., and Lamb, C. (1998). A plant homolog of the neutrophil NADPH oxidase gp91phox subunit gene encodes a plasma membrane protein with $\mathrm{Ca} 2+$ binding motifs. Plant Cell 10, 255-266. doi: 10.1105/tpc.10.2.255

Kimura, S., Kaya, H., Kawarazaki, T., Hiraoka, G., Senzaki, E., Michikawa, M., et al. (2012). Protein phosphorylation is a prerequisite for the $\mathrm{Ca} 2+$-dependent activation of Arabidopsis NADPH oxidases and may function as a trigger for the positive feedback regulation of $\mathrm{Ca}^{2+}$ and reactive oxygen species. Biochim. Biophys. Acta 1823, 398-405 doi: 10.1016/j.bbamcr.2011.09.011

Kong, J., Gong, J., Zhang, Z., Zhang, G., and Chen, S. (2003). A new AOX homologous gene from rice (Oryza sativa L.) with an alternative splicing mechanism under salt stress. Theor. Appl. Genet. 107, 326-331. doi: $10.1007 /$ s00122-003-1250-Z 
Krieger-Liszkay, A. (2005). Singlet oxygen production in photosynthesis. J. Exp. Bot. 56, 337-346. doi: 10.1093/jxb/erh237

Krieger-Liszkay, A., and Feilke, K. (2016). The dual role of the plastid terminal oxidase PTOX: between a protective and a pro-oxidant function. Front. Plant Sci. 6:1147. doi: 10.3389/fpls.2015.01147

Krinsky, N. I. (1989). Antioxidant functions of carotenoids. Free Radic. Biol. Med. 7, 617-635. doi: 10.1016/0891-5849(89)90143-3

Kumar, R. G., Shah, K., and Dubey, R. S. (2000). Salinity induced behavioural changes in malate dehydrogenase and glutamate dehydrogenase activities in rice seedlings of differing salt tolerance. Plant Sci. 156, 23-34. doi: $10.1016 /$ S0168-9452(00)00224-7

Kuntz, M. (2004). Plastid terminal oxidase and its biological significance. Planta 218, 896-899. doi: 10.1007/s00425-004-1217-6

Kurusu, T., Kuchitsu, K., and Tada, Y. (2015). Plant signaling networks involving $\mathrm{Ca}^{2+}$ and Rboh/Nox-mediated ROS production under salinity stress. Front. Plant Sci. 6:427. doi: 10.3389/fpls.2015.00427

Kwak, J. M., Mori, I. C., Pei, Z. M., Leonhardt, N., Torres, M. A., Dangl, J. L., et al. (2003). NADPH oxidase AtrbohD and AtrbohF genes function in ROS-dependent ABA signaling in Arabidopsis. EMBO J. 22, 2623-2633. doi: 10.1093/emboj/cdg277

Lambeth, J. D. (2004). Nox enzymes and the biology of reactive oxygen. Nat. Rev. Immunol. 4, 181-189. doi: 10.1038/nri1312

Lázaro, J. J., Jiménez, A., Camejo, D., Iglesias-Baena, I., Martí, M. C., Lázaro-Payo, A., et al. (2013). Dissecting the integrative antioxidant and redox systems in plant mitochondria. Effect of stress and S-nitrosylation. Front. Plant Sci. 4:460. doi: $10.3389 /$ fpls.2013.00460

Lee, Y. P., Kim, S. H., Bang, J. W., Lee, H. S., Kwak, S. S., and Kwon, S. Y. (2007). Enhanced tolerance to oxidative stress in transgenic tobacco plants expressing three antioxidant enzymes in chloroplasts. Plant Cell Rep. 26, 591-598. doi: 10.1007/s00299-006-0253-z

Leshem, Y., Seri, L., and Levine, A. (2007). Induction of phosphatidylinositol 3kinase-mediated endocytosis by salt stress leads to intracellular production of reactive oxygen species and salt tolerance. Plant J. 51, 185-197. doi: 10.1111/j.1365-313X.2007.03134.x

Li, C. R., Liang, D. D., Li, J., Duan, Y. B., Li, H., Yang, Y. C., et al. (2013). Unravelling mitochondrial retrograde regulation in the abiotic stress induction of rice Alternative oxidase 1 gene. Plant Cell Environ. 36, 775-788. doi: $10.1111 /$ pce. 12013

Li, Y. J., Hai, R. L., Du, X. H., Jiang, X. N., and Lu, H. (2009). Over-expression of a Populus peroxisomal ascorbate peroxidase (PpAPX) gene in tobacco plants enhances stress tolerance. Plant Breed. 128, 404-410. doi: 10.1111/j.14390523.2008.01593.x

Li, Y., Sommerfeld, M., Chen, F., and Hu, Q. (2008). Consumption of oxygen by astaxanthin biosynthesis: a protective mechanism against oxidative stress in Haematococcus pluvialis (Chlorophyceae). J. Plant Physiol. 165, 1783-1797. doi: 10.1016/j.jplph.2007.12.007

Lin, K. H., and Pu, S. F. (2010). Tissue- and genotype-specific ascorbate peroxidase expression in sweet potato in response to salt stress. Biol. Planta 54, 664-670. doi: 10.1007/s10535-010-0118-8

Liu, H., Xin, Z., and Zhang, Z. (2011). Changes in activities of antioxidantrelated enzymes in leaves of resistant and susceptible wheat inoculated with Rhizoctonia cerealis. Agric. Sci. China 10, 526-533. doi: 10.1016/S16712927(11)60033-3

López-Huertas, E., Corpas, F. J., Sandalio, L. M., and Del Rio, L. A. (1999). Characterization of membrane polypeptides from pea leaf peroxisomes involved in superoxide radical generation. Biochem. J. 337, 531-536. doi: $10.1042 / \mathrm{bj} 3370531$

Lu, Z., Liu, D., and Liu, S. (2007). Two rice cytosolic ascorbate peroxidases differentially improve salt tolerance in transgenic Arabidopsis. Plant Cell Rep. 26, 1909-1917. doi: 10.1007/s00299-007-0395-7

Luo, X., Wu, J., Li, Y., Nan, Z., Guo, X., Wang, Y., et al. (2013). Synergistic effects of GhSOD1 and GhCAT1 overexpression in cotton chloroplasts on enhancing tolerance to Methyl viologen and salt stresses. PLOS ONE 8:54002. doi: 10.1371/journal.pone.0054002

Ma, L., Zhang, H., Sun, L., Jiao, Y., Zhang, G., Miao, C., et al. (2012). NADPH oxidase AtrbohD and AtrbohF function in ROS-dependent regulation of $\mathrm{Na}^{+} / \mathrm{Ka}^{+}$homeostasis in Arabidopsis under salt stress. J. Exp. Bot. 63, 305-317. doi: $10.1093 / \mathrm{jxb} / \mathrm{err} 280$

Marino, D., Dunand, C., Puppo, A., and Pauly, N. (2012). A burst of plant NADPH oxidases. Trends Plant Sci. 17, 9-15. doi: 10.1016/j.tplants.2011.10.001
Marti, M. C., Florez-Sarasa, I., Camejo, D., Miquel Ribas-Carbo, M., Lazaro, J. J., Sevilla, F., et al. (2011). Response of mitochondrial thioredoxin PsTrxo1, antioxidant enzymes, and respiration to salinity in pea (Pisum sativum L.) leaves. J. Exp. Bot. 62, 3863-3874. doi: 10.1093/jxb/err076

Martinez, C., Montillet, J. L., Bresson, E., Agnel, J. P., Dai, G. H., Daniel, J. F., et al. (1998). Apoplastic peroxidase generates superoxide anions in cells of cotton cotyledons undergoing the hypersensitive reaction to Xanthomonas campestris pv. malvacearum 18. Mol. Plant Microbe Inter. 11, 1038-1047. doi: 10.1094/MPMI.1998.11.11.1038

Matysik, J., Bhalu, B. A., and Mohanty, P. (2002). Molecular mechanisms of quenching of reactive oxygen species by proline under stress in plants. Curr. Sci. 82, 525-532. http://www.iisc.ernet.in/currsci/mar102002/525.pdf

Mehler, A. H. (1951). Studies on reactions of illuminated chloroplasts. I. Mechanisms of the reduction of oxygen and other Hill reagents. Arch. Biochem. Biophys. 33, 65-77. doi: 10.1016/0003-9861(51)90082-3

Miller, G., Schlauch, K., Tam, R., Cortes, D., Torres, M. A., Shulaev, V., et al. (2009). The plant NADPH oxidase RBOHD mediates rapid systemic signaling in response to diverse stimuli. Sci. Sign. 2, 45. doi: 10.1126/scisignal.2000448

Miller, G., Suzuki, N., Ciftci-Yilmaz, S., and Mittler, R. (2010). Reactive oxygen species homeostasis and signalling during drought and salinity stresses. Plant Cell Environ. 33, 453-467. doi: 10.1111/j.1365-3040.2009.02041.x

Mishra, P., Kumari, B., and Dubey, R. S. (2013). Differential responses of antioxidative defense system to prolonged salinity stress in salt-tolerant and salt-sensitive Indica rice (Oryza sativa L.) seedlings. Protoplasma 250, 3-19. doi: 10.1007/s00709-011-0365-3

Mishra, S., Jha, A. B., and Dubey, R. S. (2011). Arsenite treatment induces oxidative stress, upregulates antioxidant system, and causes phytochelatin synthesis in rice seedlings. Protoplasma 248, 565-577. doi: 10.1007/s00709-010-0210-0

Mittal, R., and Dubey, R. S. (1991). Behaviour of peroxidases in rice: changes in enzymatic activity and isoforms in relation to salt tolerance. Plant Physiol. Biochem. 29, 31-40.

Mittler, R. (2002). Oxidative stress, antioxidants and stress tolerance. Trends. Plant Sci. 7, 405-410. doi: 10.1016/S1360-1385(02)02312-9

Mittler, R., Vanderauwera, S., Gollery, M., and Van Breusegem, F. (2004). Reactive oxygen gene network of plants. Trends. Plant Sci. 9, 490-498. doi: 10.1016/j.tplants.2004.08.009

Møller, I. M., Jensen, P. E., and Hansson, A. (2007). Oxidative modifications to cellular components in plants. Annu. Rev. Plant Biol. 58, 459-481. doi: 10.1146/annurev.arplant.58.032806.103946

Monshausen, G. B., Bibikova, T. N., Weisenseel, M. H., Gilroy, S. (2009). Ca ${ }^{2+}$ regulates reactive oxygen species production and $\mathrm{pH}$ during mechanosensing in Arabidopsis roots. Plant Cell 21, 2341-2356. doi: 10.1105/tpc.109. 068395

Monson, R. K., Edwards, G. E., and Ku, M. S. B. (1984). C3 - C4 intermediate photosynthesis in plants. BioScience 34, 563-574. doi: 10.2307/1309599

Moser, D., Nicholls, P., Wastyn, M., and Peschek, G. A. (1991). Acidic cytochrome c6 of unicellular cyanobacteria is an indispensable and kinetically competent electron donor to cytochrome oxidase in plasma and thylakoid membranes. Biochem. Int. 24, 757-768.

Munns, R., and Tester, M. (2008). Mechanisms of salinity tolerance. Annu. Rev. Plant Physiol. 59, 651-681. doi: 10.1146/annurev.arplant.59.032607.092911

Nawrocki, W. J., Tourasse, N. J., Taly, A., Rappaport, F., and Wollman, F. A. (2015). The plastid terminal oxidase: its elusive function points to multiple contributions to plastid physiology. Annu. Rev. Plant Biol. 66, 49-74. doi: 10.1146/annurev-arplant-043014-114744

Niyogi, K. K., Grossman, A. R., and Björkman, O. (1998). Arabidopsis mutants define a central role for the xanthophyll cycle in the regulation of photosynthetic energy conversion. Plant Cell 10, 1121-1134. doi: 10.1105/tpc.10.7.1121

Noctor, G., Mhamdi, A., and Foyer, C. H. (2014). The roles of reactive oxygen metabolism in drought: not so cut and dried. Plant Physiol. 164, 1636-1648. doi: $10.1104 /$ pp.113.233478

Noctor, G., Veljovic-Jovanovic, S., Driscoll, S., Novitskaya, L., and Foyer, C. (2002). Drought and oxidative load in the leaves of $\mathrm{C} 3$ plants: a predominant role for photorespiration? Ann. Bot. 89, 841-850. doi: 10.1093/aob/mcf096

Parida, A. K., Das, A. B., and Mittra, B. (2004). Effects of salt on growth, ion accumulation, photosynthesis and leaf anatomy of the mangrove Bruguiera parviflora. Trees-Struct. Funct. 18, 167-174. doi: 10.1007/s00468-003-0293-8

Peltier, G., and Cournac, L. (2002). Chlororespiration. Annu. Rev. Plant Physiol. 53, 523-550. doi: 10.1146/annurev.arplant.53.100301.135242 
Pogány, M., von Rad, U., Grün, S., Dongó, A., Pintye, A., Simoneau, P., et al. (2009). Dual roles of reactive oxygen species and NADPH oxidase RBOHD in an Arabidopsis-Alternaria pathosystem. Plant Physiol. 151, 1459-1475. doi: 10.1104/pp.109.141994

Prashanth, S. R., Sadhasivam, V., and Parida, A. (2008). Over expression of cytosolic copper/zinc superoxide dismutase from a mangrove plant Avicennia marina in indica rice var Pusa Basmati-1 confers abiotic stress tolerance. Trans. Res. 17, 281-291. doi: 10.1007/s11248-007-9099-6

Rasmusson, A. G., Geisler, D. A., and Møller, I. M. (2008). The multiplicity of dehydrogenases in the electron transport chain of plant mitochondria. Mitochondrion 8, 47-60. doi: 10.1016/j.mito.2007.10.004

Reguera, M., Bassil, E., and Blumwald, E. (2014). Intracellular NHX-type cation/H+ antiporters in plants. Mol. Plant. 7, 261-263. doi: 10.1093/mp/sst091

Rejeb, K. B., Abdelly, C., and Savouré, A. (2014). How reactive oxygen species and proline face stress together. Plant Physiol. Biochem. 80, 278-284. doi: 10.1016/j.plaphy.2014.04.007

Rejeb, K. B., Benzarti, M., Debez, A., Bailly, C., Savoure, A., and Abdelly, C. (2015a). NADPH oxidase-dependent $\mathrm{H}_{2} \mathrm{O}_{2}$ production is required for saltinduced antioxidant defense in Arabidopsis thaliana. J. Plant Physiol. 174, 5-15. doi: 10.1016/j.jplph.2014.08.022

Rejeb, K. B., Vos, D. L. D., Disquet, I. L., Leprince, A. S., Bordenave, M., Maldiney, R., et al. (2015b). Hydrogen peroxide produced by NADPH oxidases increases proline accumulation during salt or mannitol stress in Arabidopsis thaliana. New Phytol. 208, 1138-1148. doi: 10.1111/nph.13550

Rengasamy, P. (2006). World salinization with emphasis on Australia. J. Exp. Bot. 57, 1017-1023. doi: 10.1093/jxb/erj108

Rios-Gonzalez, K., Erdei, L., and Lips, S. H. (2002). The activity of antioxidant enzymes in maize and sunflower seedlings as affected by salinity and different nitrogen sources. Plant Sci. 162, 923-930. doi: 10.1016/S0168-9452(02)00040-7

Rodríguez, A. A., Maiale, S. J., Menéndez, A. B., and Ruiz, O. A. (2009). Polyamine oxidase activity contributes to sustain maize leaf elongation under saline stress. J. Exp. Bot. 60, 4249-4262. doi: 10.1093/jxb/erp256

Rogov, A. G., Sukhanova, E. I., Uralskaya, L. A., Aliverdieva, D. A., and Zvyagilskaya, R. A. (2014). Alternative oxidase: distribution, induction, properties, structure, regulation, and functions. Biochemistry 79, 1615-1634. doi: 10.1134/s0006297914130112

Rosso, D., Ivanov, A. G., Fu, A., Geisler-Lee, J., Hendrickson, L., Geisler, M., et al. (2006). IMMUTANS does not act as a stress-induced safety valve in the protection of the photosynthetic apparatus of Arabidopsis during steady-state photosynthesis. Plant Physiol. 142, 574-585. doi: 10.1104/pp.106.085886

Rubio, M. C., Bustos-Sanmamed, P., Clemente, M. R., and Becana, M. (2009). Effects of salt stress on the expression of antioxidant genes and proteins in the model legume Lotus japonicas. New Phytol. 181, 851-859. doi: 10.1111/j.14698137.2008.02718.x

Sagi, M., and Fluhr, R. (2006). Production of reactive oxygen species by plant NADPH oxidases. Plant Physiol. 141, 336-340. doi: 10.1104/pp.106.078089

Sairam, R. K., and Tyagi, A. (2004). Physiology and molecular biology of salinity stress tolerance in plants. Curr. Sci. 86, 407-421. Available online at: http:// www.iisc.ernet.in/currsci/feb102004/407.pdf

Sakamoto, A., and Murata, N. (2000). Genetic engineering of glycinebetaine synthesis in plants: current status and implications for enhancement of stress tolerance. J. Exp. Bot. 51, 81-88. doi: 10.1093/jexbot/51.342.81

Sakamoto, H., Matsuda, O., and Iba, K. (2008). ITN1, a novel gene encoding an ankyrin-repeat protein that affects the ABA-mediated production of reactive oxygen species and is involved in salt-stress tolerance in Arabidopsis thaliana. Plant J. 56, 411-422. doi: 10.1111/j.1365-313X.2008.03614.x

Scheibe, R., Backhausen, J. E., Emmerlich, V., and Holtgrefe, S. (2005). Strategies to maintain redox homeostasis during photosynthesis under changing conditions. J. Exp. Bot. 56, 1481-1489. doi: 10.1093/jxb/eri181

Shalata, A., Mittova, V., Volokita, M., Guy, M., and Tal, M. (2001). Response of the cultivated tomato and its wild salt-tolerant relative Lycopersicon pennellii to salt-dependent oxidative stress: the root antioxidative system. Physiol. Plant. 112, 487-494. doi: 10.1034/j.1399-3054.2001.1120405.x

Sharma, P., Jha, A. B., Dubey, R. S., and Pessarakl, M. (2012). Reactive oxygen species, oxidative damage, and antioxidative defensemechanism in plants under stressful conditions. J. Bot. 2012, 1-26. doi: 10.1155/2012/217037

Sharma, P. K., and Hall, D. O. (1992). Changes in carotenoid composition and photosynthesis in sorghum under high light and salt stresses. J. Plant Physiol. 140, 661-666. doi: 10.1016/S0176-1617(11)81020-5
Shi, W. M., Muramoto, Y., Ueda, A., and Takabe, T. (2001). Cloning of peroxisomal ascorbate peroxidase gene from barley and enhanced thermotolerance by overexpressing in Arabidopsis thaliana. Gene 273, 23-27. doi: 10.1016/S03781119(01)00566-2

Smith, C. A., Melino, V. J., Sweetman, C., and Soole, K. L. (2009). Manipulation of alternative oxidase can influence salt tolerance in Arabidopsis thaliana. Physiol. Plant. 137, 459-472. doi: 10.1111/j.1399-3054.2009.01305.x

Song, Y., Ji, D., Li, S., Wang, P., Li, Q., and Xiang, F. (2012). Thedynamicchanges of DNA methylation and histone modifications of salt responsive transcription factor genes in soybean. PLoS ONE 7:41274. doi: 10.1371/journal.pone. 0041274

Srivastava, A. K., Srivastava, S., Lokhande, V. H., D'Souza, S. F., and Suprasanna, P. (2015). Salt stress reveals differential antioxidant and energetics responses in glycophyte (Brassica juncea L.) and halophyte (Sesuvium portulacastrum L.). Front. Environ. Sci. 3:19. doi: 10.3389/fenvs.2015.00019

Srivastava, S., and Dubey, R. S. (2011). Manganese-excess induces oxidative stress, lowers the pool of antioxidants and elevates activities of key antioxidative enzymes in rice seedlings. Plant Gro. Reg. 64, 1-16. doi: 10.1007/s10725-0109526-1

Stepien, P., and Johnson, G. N. (2009). Contrasting responses of photosynthesis to salt stress in the glycophyte arabidopsis and the halophyte Thellungiella: role of the plastid terminal oxidase as an alternative electron sink. Plant Physiol. 149, 1154-1165. doi: 10.1104/pp.108.132407

Stepien, P., and Klobus, G. (2005). Antioxidant defense in the leaves of C3 and C4 plants under salinity stress. Physiol. Plant. 125, 31-40. doi: 10.1111/j.13993054.2005.00534.x

Strand, D. D., Livingston, A. K., Satoh-Cruz, M., Froehlich, J. E., Maurino, V. G., and Kramer, D. M. (2015). Activation of cyclic electron flow by hydrogen peroxide in vivo. Proc. Natl. Acad. Sci. U.S.A. 112, 5539-5544. doi: $10.1073 /$ pnas. 1418223112

Sun, W. H., Duan, M., Shu, D. F., Yang, S., and Meng, Q. W. (2010). Overexpression of StAPX in tobacco improves seed germination and increases early seedling tolerance to salinity and osmotic stresses. Plant Cell Rep. 29, 917-926. doi: 10.1007/s00299-010-0878-9

Suzuki, N., Koussevitzky, S., Mittler, R., and Miller, G. (2012). ROS and redox signalling in the response of plants to abiotic stress. Plant Cell Environ. 35, 259-270. doi: 10.1111/j.1365-3040.2011.02336.x

Suzuki, N., Miller, G., Morales, J., Shulaev, V., Torres, M. A., and Mittler, R. (2011). Respiratory burst oxidases: the engines of ROS signaling. Curr. Opin. Plant Biol. 14, 691-699. doi: 10.1016/j.pbi.2011.07.014

Szekely, G., Abraham, E., Cselo, A., Rigo, G., Zsigmond, L., Csiszar, J., et al. (2008). Duplicated P5CS genes of Arabidopsis play distinct roles in stress regulation and developmental control of proline biosynthesis. Plant J. 53, 11-28. doi: 10.1111/j.1365-313X.2007.03318.x

Taji, T., Seki, M., Satou, M., Sakurai, T., Kobayashi, M., Ishiyama, K., et al. (2004). Comparative genomics in salt tolerance between Arabidopsis and Arabidopsisrelated halophyte salt cress using Arabidopsis microarray. Plant Physiol. 135, 1697-1709. doi: 10.1104/pp.104.039909

Tanaka, Y., Hibino, T., Hayashi, Y., Tanaka, A., Kishitani, S., Takabe, T., et al. (1999). Salt tolerance of transgenic rice overexpressing yeast mitochondrial Mn-SOD in chloroplasts. Plant Sci. 148, 131-138. doi: 10.1016/S01689452(99)00133-8

Taniguchi, M., and Miyake, H. (2012). Redox-shuttling between chloroplast and cytosol: integration of intra-chloroplast and extra-chloroplast metabolism. Curr. Opin. Plant Biol. 15, 252-260. doi: 10.1016/j.pbi.2012.01.014

Torres, M. A., Dangl, J. L., and Jones, J. D. G. (2002). Arabidopsis gp91phox homologues AtrbohD and AtrbohF are required for accumulation of reactive oxygen intermediates in the plant defense response. Proc. Natl. Acad. Sci. U.S.A. 99, 517-522. doi: 10.1073/pnas.012452499

Trouillard, M., Shahbazi, M., Moyet, L., Rappaport, F., Joliot, P., Kuntz, M., et al. (2012). Kinetic properties and physiological role of the plastoquinone terminal oxidase (PTOX) in a vascular plant. Biochim. Biophys. Acta 1817, 2140-2148. doi: 10.1016/j.bbabio.2012.08.006

Tsai, Y. C., Hong, C. Y., Liu, L. F., and Kao, C. H. (2005). Expression of ascorbate peroxidase and glutathione reductase in roots of rice seedlings in response to $\mathrm{NaCl}$ and $\mathrm{H}_{2} \mathrm{O}_{2}$. J. Plant Physiol. 162, 291-299. doi: 10.1016/j.jplph.2004. 06.004

Tuna, A. L., Kaya, C., Dikilitas, M., and Higgs, D. (2008). The combined effects of gibberellic acid and salinity on some antioxidant enzyme activities, plant 
growth parameters and nutritional status in maize plants. Env. Exp. Bot. 62, 1-9. doi: 10.1016/j.envexpbot.2007.06.007

Uzilday, B., Turkan, I., Ozgur, R., and Sekmen, A. H. (2014). Strategies of ROS regulation and antioxidant defense during transition from C-3 to C-4 photosynthesis in the genus Flaveria under PEG-induced osmotic stress. J. Plant Physiol. 171, 65-75. doi: 10.1016/j.jplph.2013.06.016

Vaidyanathan, H., Sivakumar, P., Chakrabarty, R., and Thomas, G. (2003). Scavenging of reactive oxygen species in $\mathrm{NaCl}$ stressed rice (Oryza sativa L.) - Differential response in salt tolerant and sensitive varieties. Plant Sci. 165, 1411-1418. doi: 10.1016/j.plantsci.2003.08.005

Valderrama, R., Corpas, F. J., Carreras, A., Gómez-Rodríguez, M. V., Chaki, M., Pedrajas, J. R., et al. (2006). The dehydrogenase-mediated recycling of NADPH is a key antioxidant system against salt-induced oxidative stress in olive plants. Plant Cell Environ. 29, 1449-1459. doi: 10.1111/j.1365-3040.2006.01530.x

Van Aken, O. V., Giraud, E., Clifton, R., and Whelan, J. (2009). Alternative oxidase: a target and regulator of stress responses. Physiol. Plant. 137, 354-361. doi: 10.1111/j.1399-3054.2009.01240.x

Van Camp, W., Capiau, K., Van Montagu, M., Inze, D., and Slooten, L. (1996). Enhancement of oxidative stress tolerance in transgenic tobacco plants overproducing Fe-superoxide dismutase in chloroplasts. Plant Physiol. 112, 1703-1714. doi: 10.1104/pp.112.4.1703

Verslues, P. E., Agarwal, M., Katiyar-Agarwal, S., Zhu, J., and Zhu, J. (2006). Methods and concepts in quantifying resistance to drought, salt and freezing, abiotic stresses that affect plant water status. Plant J. 45, 523-539. doi: 10.1111/j.1365-313X.2005.02593.x

Voss, I., Sunil, B., Scheibe, R., and Raghavendra, A. S. (2013). Emerging concept for the role of photorespiration as an important part of abiotic stress response. Plant Biol. 15, 713-722. doi: 10.1111/j.1438-8677.2012.00710.x

Waie, B., and Rajam, M. V. (2003). Effect of increased polyamine biosynthesis on stress responses in transgenic tobacco by introduction of human Sadenosylmethionine gene. Plant Sci. 164, 727-734. doi: 10.1016/S01689452(03)00030-X

Wang, H., Liang, X., Huang, J., Zhang, D., Lu, H., Liu, Z., et al. (2010). Involvement of ethylene and hydrogen peroxide in induction of alternative respiratory pathway in salt-treated Arabidopsis calluses. Plant Cell Physiol. 51, 1754-1765. doi: $10.1093 /$ pcp/pcq134

Wang, J., Sommerfeld, M., and Hu, Q. (2009). Occurrence and environmental stress responses of two plastid terminal oxidases in Haematococcus pluvialis (Chlorophyceae). Planta 230, 191-203. doi: 10.1007/s00425-009-0932-4

Wang, Y., Wisniewski, M., Meilan, R., Cui, M., Webb, R., and Fuchigami, L. (2005). Overexpression of cytosolic ascorbate peroxidase in tomato confers tolerance to chilling and salt stress. J. Amer. Soc. Hort. Sci. 130, 167-173. https://www. researchgate.net/publication/267968552

Wiciarza, M., Gubernatorb, B., Jerzy Kruka, J., and Niewiadomskac, E. (2015). Enhanced chloroplastic generation of $\mathrm{H}_{2} \mathrm{O}_{2}$ in stress-resistant Thellungiella salsuginea in comparison to Arabidopsis thaliana. Physiol. Plant. 153, 467-476. doi: $10.1111 /$ ppl.12248
Winger, A. M., Taylor, N. L., Heazlewood, J. L., Day, D. A., and Millar, A. H. (2007). Identification of intra- and intermolecular disulphide bonding in the plant mitochondrial proteome by diagonal gel electrophoresis. Proteomics 7 , 4158-4170. doi: 10.1002/pmic.200700209

Wingler, A., Lea, P. J., Quick, W. P., and Leegood, R. C. (2000). Photorespiration: metabolic pathways and their role in stress protection. Philos. Trans. R. Soc. Lond. B Biol. Sci. 355, 1517-1529. doi: 10.1098/rstb. 2000.0712

Wojtaszek, P. (1997). Oxidative burst: an early plant response to pathogen infection. Biochem. J. 322, 681-692. doi: 10.1042/bj3220681

Xie, Y. J., Xu, S., Han, B., Wu, M. Z., Yuan, X. X., Han, Y., et al. (2011). Evidence of Arabidopsis salt acclimation induced by up-regulation of $\mathrm{HY} 1$ and the regulatory role of $\mathrm{RbohD}$-derived reactive oxygen species synthesis. Plant J. 66, 280-292. doi: 10.1111/j.1365-313X.2011. 04488.x

Yoshida, K., Watanabe, C. K., Hachiya, T., Tholen, D., Shibata, M., Terashima, I., et al. (2011). Distinct responses of the mitochondrial respiratory chain to long- and short-term high-light environments in Arabidopsis thaliana. Plant Cell Environ. 34, 618-628. doi: 10.1111/j.1365-3040.2010. 02267.x

Yu, Q., Feilke, K., Krieger-Liszkay, A., and Beyer, P. (2014). Functional and molecular characterization of plastid terminal oxidase from rice (Oryza sativa). Biochim. Biophys. Acta 1837, 1284-1292. doi: 10.1016/j.bbabio.2014. 04.007

Zeng, L., Lesch, S. M., and Grieve, C. M. (2003). Rice growth and yield respond to changes in water depth and salinity stress. Agril. Water Manag. 59, 67-75. doi: 10.1016/S0378-3774(02)00088-4

Zhang, D. W., Yuan, S., Xu, F., Zhu, F., Yuan, M., Ye, H. X., et al. (2016). Light intensity affects chlorophyll synthesis during greening process by metabolite signal from mitochondrial alternative oxidase in Arabidopsis. Plant Cell Environ. 39, 12-25. doi: 10.1111/pce.12438

Zhang, Y., Lai, J., Sun, S., Li, Y., Liu, Y., Liang, L., et al. (2008). Comparison analysis of transcripts from the halophyte Thellungiella halophila. J. Integr. Plant. Biol. 50, 1327-1335. doi: 10.1111/j.1744-7909.2008.00740.x

Zhu, J. K. (2001). Plant salt tolerance. Trends Plant Sci. 6, 66-71. doi: $10.1016 /$ S1360-1385(00)01838-0

Conflict of Interest Statement: The authors declare that the research was conducted in the absence of any commercial or financial relationships that could be construed as a potential conflict of interest.

Copyright $\odot 2016$ Hossain and Dietz. This is an open-access article distributed under the terms of the Creative Commons Attribution License (CC BY). The use, distribution or reproduction in other forums is permitted, provided the original author(s) or licensor are credited and that the original publication in this journal is cited, in accordance with accepted academic practice. No use, distribution or reproduction is permitted which does not comply with these terms. 